\title{
Dynamic Interaction of $I_{\mathrm{h}}$ and $I_{\mathrm{K}-\mathrm{LVA}}$ during Trains of Synaptic Potentials in Principal Neurons of the Medial Superior Olive
}

\author{
Sukant Khurana, ${ }^{1 \star}$ Michiel W. H. Remme, ${ }^{2 *}$ John Rinzel, ${ }^{2,3}$ and Nace L. Golding ${ }^{1}$ \\ ${ }^{1}$ Section of Neurobiology and Institute for Neuroscience, University of Texas at Austin, Austin, Texas 78712-0248, ${ }^{2}$ Center for Neural Science, New York \\ University, New York, New York 10003, and ${ }^{3}$ Courant Institute of Mathematical Sciences, New York University, New York, New York 10012
}

In neurons of the medial superior olive (MSO), voltage-gated ion channels control the submillisecond time resolution of binaural coincidence detection, but little is known about their interplay during trains of synaptic activity that would be experienced during auditory stimuli. Here, using modeling and patch-clamp recordings from MSO principal neurons in gerbil brainstem slices, we examined interactions between two major currents controlling subthreshold synaptic integration: a low-voltage-activated potassium current $\left(I_{\mathrm{K}-\mathrm{LVA}}\right)$ and a hyperpolarization-activated cation current $\left(I_{\mathrm{h}}\right)$. Both $I_{\mathrm{h}}$ and $I_{\mathrm{K}-\mathrm{LVA}}$ contributed strongly to the resting membrane conductance and, during trains of simulated EPSPs, exhibited cumulative deactivation and inactivation, respectively. In current-clamp recordings, regular and irregular trains of simulated EPSCs increased input resistance up to 60\%, effects that accumulated and decayed (after train) over hundreds of milliseconds. Surprisingly, the mean voltage and peaks of EPSPs increased by only a few millivolts during trains. Using a model of an MSO cell, we demonstrated that the nearly uniform response during modest depolarizing stimuli relied on changes in $I_{\mathrm{h}}$ and $I_{\mathrm{K}-\mathrm{LVA}}$, such that their sum remained nearly constant over time. Experiments and modeling showed that, for simplified binaural stimuli (EPSC pairs in a noisy background), spike probability gradually increased in parallel with the increasing input resistance. Nevertheless, the interplay between $I_{\mathrm{h}}$ and $I_{\mathrm{K}-\mathrm{LVA}}$ helps to maintain a nearly uniform shape of individual synaptic responses, and we show that the time resolution of synaptic coincidence detection can be maintained during trains if EPSC size gradually decreases (as in synaptic depression), counteracting slow increases in excitability.

\section{Introduction}

The principal neurons of the medial superior olive (MSO) serve as the first stage for processing low-frequency binaural acoustic information. They signal the degree of temporal coincidence of inputs to the two ears through changes in their firing rate output (for review, see Grothe, 2003; Joris and Yin, 2007). Apart from specializations in circuitry and synaptic receptors, voltage-gated ion channels play critical roles in establishing a narrow time window over which binaural activity is integrated, enabling the transformation of phase-locked, temporally precise information into cues used for localizing sounds along the azimuth (Svirskis et al., 2002; Scott et al., 2005, 2010).

Low-voltage-activated potassium channels ( $\left.I_{\mathrm{K}-\mathrm{LVA}}\right)$ and hyperpolarization-activated cation channels $\left(I_{\mathrm{h}}\right)$ are the two major conductances in the MSO that are activated throughout the subthreshold voltage range (Svirskis et al., 2004; Scott et al., 2005; Mathews et al., 2010). $I_{\mathrm{h}}$ contributes to the resting membrane

Received March 1, 2011; revised April 14, 2011; accepted April 14, 2011.

Author contributions: S.K., M.W.H.R., J.R., and N.L.G. designed research; S.K., M.W.H.R., and N.L.G. performed research; S.K., M.W.H.R., and J.R. analyzed data; S.K., M.W.H.R., J.R., and N.L.G. wrote the paper.

This work was supported by NIH Grants R01 DC006788 (N.L.G.) and R01 DC008543-01 (J.R.).

*S.K. and M.W.H.R. contributed equally to this work.

Correspondence should be addressed to Nace L. Golding, Section of Neurobiology, 1 University Station, C0920, University of Texas at Austin, Austin, TX 78712-0248. E-mail: golding@mail.utexas.edu.

DOI:10.1523/JNEUROSCI.1079-11.2011

Copyright $\odot 2011$ the authors $\quad 0270-6474 / 11 / 318936-12 \$ 15.00 / 0$ conductance of many neurons early in the auditory pathway, in turn sharpening the temporal precision of firing (Banks and Smith, 1992; Golding et al., 1995; Mo and Davis, 1997; Bal and Oertel, 2000; Yamada et al., 2005; K. E. Leao et al., 2006; Hassfurth et al., 2009). $I_{\mathrm{K}-\mathrm{LVA}}$ is also present in many cell types in early stations of auditory processing, increasing the signal-to-noise ratio and enhancing the precision of phase-locking (Reyes et al., 1994; Rathouz and Trussell, 1998; Bal and Oertel, 2001; Svirskis et al., 2002; Barnes-Davies et al., 2004; Kuba et al., 2005; Scott et al., 2005).

Previous studies have focused on the dynamics of these currents on a short timescale, during the integration of one or few synaptic inputs. However, natural sound presents long trains of synaptic inputs to MSO neurons. Here, with experiments and modeling, we examine the dynamics of $I_{\mathrm{h}}$ and $I_{\mathrm{K}-\mathrm{LVA}}$ during such ongoing trains of EPSPs and determine how the interplay of these currents affects input integration. Both $I_{\mathrm{h}}$ and $I_{\mathrm{K}-\mathrm{LVA}}$ change slowly during and after long trains but in a counterbalanced manner. This balancing leads to little change in mean membrane potential and EPSP amplitude during the train and induces rapid repolarization after stimulus termination. Despite the stability of EPSP amplitude, the input trains result in a significant increase of the input resistance that outlasts the stimulus. Although the increase in input resistance is associated with increased spike probability of MSO neurons, high temporal resolution is still retained, thereby enabling the precise coincidence detection of synaptic inputs during ongoing stimuli. The stabilization of EPSP amplitude 
and mean membrane potential during trains by $I_{\mathrm{h}}$ and $I_{\mathrm{K}-\mathrm{LVA}}$ may be an important mechanism to help MSO neurons maintain a more uniform integrative window for binaural coincidence detection across stimuli that exhibit different temporal and amplitude characteristics.

\section{Materials and Methods}

Slice preparation. All experimental procedures followed the guidelines of the National Institutes of Health and were approved by the Institutional Animal Care and Use Committee at the University of Texas at Austin. Both male and female Mongolian gerbils (Meriones unguiculatus, P18P22) were obtained from Charles River Laboratories or bred at the Animal Resource Center of the University of Texas at Austin. Gerbils were anesthetized with $5 \%$ halothane, and the brain removed while submerged in warmed $\left(32^{\circ} \mathrm{C}\right.$ ), oxygenated artificial CSF (ACSF) (in mM: 125 $\mathrm{NaCl}, 2.5 \mathrm{KCl}, 2 \mathrm{CaCl}_{2}, 1.0 \mathrm{MgCl}_{2}, 20 \mathrm{NaHCO}_{3}, 1.25 \mathrm{NaH}_{2} \mathrm{PO}_{4}$, and 25 glucose, pH 7.45 with $\mathrm{NaOH}$ ). Horizontal sections $200 \mu \mathrm{m}$ thick were cut using an oscillating tissue slicer (Leica VT-1000S and VT-1200S) and were then transferred to an incubating chamber containing oxygenated $\mathrm{ACSF}$ at $35^{\circ} \mathrm{C}$. After $30 \mathrm{~min}$, slices were held at room temperature until recording. Individual slices were transferred to a recording stage, bathed with oxygenated ACSF, and maintained at $35 \pm 0.1^{\circ} \mathrm{C}$ during recording.

Whole-cell voltage-clamp recordings. MSO neurons were visualized using infrared differential interference contrast (IR-DIC) microscopy (Axioskop 2FS; Carl Zeiss) in combination with a Newvicon tube camera (Dage-MTI). Borosilicate patch pipettes (1.65 mm outer diameter; World Precision Instruments) were heat polished and had open tip resistances of $2-4 \mathrm{M} \Omega$ when filled with a potassium-based internal solution. For $I_{\mathrm{h}}$ measurements, the pipette solution contained the following (in $\mathrm{mm}$ ): 127 potassium gluconate, $8 \mathrm{KCl}, 10$ sodium phosphocreatine, 10 HEPES, 0.5 EGTA, 4 MgATP, and 0.3 NaGTP, pH 7.3, with KOH. $I_{\mathrm{h}}$ was isolated pharmacologically by including the following in normal ACSF (in mM): 13,4-diaminopyridine, 10 tetraethylammonium-Cl, 0.2 4-AP, $0.2 \mathrm{BaCl}_{2}, 0.001 \mathrm{TTX}, 0.05 \mathrm{NiCl}_{2}$, and $0.2 \mathrm{CoCl}_{2}$. These drugs block voltage-gated and inwardly rectifying potassium currents as well as voltagegated sodium and calcium currents. In addition, $10 \mu \mathrm{M}$ CNQX, $50 \mu \mathrm{M}$ AP-5, and $2 \mu \mathrm{M}$ strychnine was included in the ACSF to block AMPA, NMDA, and glycine receptors. In some experiments, $50 \mu \mathrm{M}$ ZD7288 (4-ethylphenylamino-1,2-dimethyl-6-methylaminopyrimidinium chloride) was added to the bath or $20 \mu \mathrm{M}$ to the intracellular solution to block $I_{\mathrm{h}}$. All synaptic blockers were obtained from Tocris Bioscience except for strychnine, which was obtained from Sigma.

$I_{\mathrm{K}-\mathrm{LVA}}$ was isolated pharmacologically by including the following in the normal ACSF (in mM): $0.05 \mathrm{ZD} 7288,0.2 \mathrm{BaCl}_{2}, 0.001 \mathrm{TTX}, 0.05$ $\mathrm{NiCl}_{2}$, and $0.2 \mathrm{CoCl}_{2}$, along with $10 \mu \mathrm{M} \mathrm{CNQX,} 50 \mu \mathrm{M} \mathrm{AP-5}$, and $2 \mu \mathrm{M}$ strychnine to block synaptic activity.

Data were recorded with an Axopatch 200B amplifier (Molecular Devices), filtered at $1 \mathrm{kHz}$ for $I_{\mathrm{h}}$ recordings and at $5 \mathrm{kHz}$ for $I_{\mathrm{K}-\mathrm{LVA}}$ recordings, digitized at $50 \mathrm{kHz}$, and acquired using custom macros programmed in IgorPro (Wavemetrics). Wrapping electrodes with Parafilm reduced stray electrode capacitance, and the remaining capacitance was further reduced using the electrode capacitance compensation circuitry of the amplifier. Series resistance and whole-cell capacitance were compensated by $85-95 \%$. All voltages reported are corrected for a liquid junction potential of $9 \mathrm{mV}$. To examine $I_{\mathrm{h}}$ deactivation and $I_{\mathrm{K}-\mathrm{LVA}}$ inactivation during EPSPs in voltage clamp, a synaptically evoked EPSP recorded in current clamp was scaled to different peak voltages and concatenated with itself to form a stimulus train at $500 \mathrm{~Hz}$. All voltage-clamp recordings were included only if the series resistance was $<10 \mathrm{M} \Omega$.

Whole-cell current-clamp recordings. Whole-cell current-clamp recordings were made from visually identified MSO principal neurons using the same potassium gluconate-based solution used in voltageclamp recordings and using pipettes with open tip resistances of $2-5 \mathrm{M} \Omega$. The current-clamp recordings were made using Dagan BVC-700A amplifiers in current-clamp mode using bridge balance and capacitance compensation. Recordings were included if the series resistance was $<15$ $\mathrm{M} \Omega$ and the resting membrane potential was negative to $-55 \mathrm{mV}$. Data were low-pass filtered at $5 \mathrm{kHz}$ and acquired to computer at $50 \mathrm{kHz}$. All recordings were corrected for a liquid junction potential of $9 \mathrm{mV}$. Simulated EPSC waveforms (current injections) were mimicked using an $\alpha$ function with a time constant $(\tau)$ of $0.2 \mathrm{~ms}$. Stimulus-induced changes in input resistance were calculated using brief hyperpolarizing pulses (3-5 $\mathrm{mV}, 10 \mathrm{~ms}$ duration) before and after the sEPSC stimulus (150 and 10 ms, respectively).

Data analyses. All analyses were performed using IgorPro. In currentclamp experiments, peak and steady-state $I-V$ plots were generated from peak voltage responses to $100 \mathrm{~ms}$ current steps. The input resistance was obtained from the slope of the peak $I-V$ plot between 0 and $10 \mathrm{mV}$ below rest. The membrane time constant was obtained from a singleexponential fit from baseline to the peak of a hyperpolarizing voltage response (3-5 $\mathrm{mV}$ from rest). Relative changes in input resistance $\left(R_{\mathrm{N}}\right)$ during trains of synaptic-like depolarizations were quantified as $\left[\left(R_{\mathrm{N}(\text { posttrain })}-R_{\mathrm{N}(\text { pretrain })}\right) / R_{\mathrm{N}(\text { pretrain })}\right] * 100$.

In voltage-clamp experiments, the voltage dependence of $I_{\mathrm{h}}$ activation was measured from peak tail currents arising from a step to $-100 \mathrm{mV}$ after $1 \mathrm{~s}$ prepulses to voltages between -30 and $-110 \mathrm{mV}$ in $10 \mathrm{mV}$ increments. These currents were normalized to maximum and minimum values. The normalized $g-V$ curve was fit with a Boltzmann equation of the following form: $f(V)=1 /\left(1+\exp \left[\left(V_{1 / 2}-V\right) / k\right]\right)$, where $V$ is the membrane voltage, $V_{1 / 2}$ is the half-maximal activation voltage, and $k$ is the slope factor. To measure the reversal potential, $I_{\mathrm{h}}$ was activated with a $1 \mathrm{~s}$ pulse to $-100 \mathrm{mV}$, followed by steps to between -100 and $-30 \mathrm{mV}$. Instantaneous tail currents were plotted versus membrane potential, and the reversal potential was calculated from the zero crossing of the linear fit. For group comparisons, means are presented \pm SEM and statistical significance was assessed using either a two-way ANOVA or Student's $t$ test at a significance level of 0.05 .

Computational modeling. We constructed a single-compartment model including the three central subthreshold membrane currents: the voltage-dependent $\mathrm{K}_{\mathrm{LVA}}$-type and h-type currents and a leak current. The $I_{\mathrm{h}}$ model was based on our experimental data and fit using Neurofit (Willms, 2002). Its kinetics are described by the sum of a fast $\left(r_{\mathrm{f}}\right)$ and a slow $\left(r_{\mathrm{s}}\right)$ gating variable, both using the same activation function $r_{\infty}$. The $I_{\mathrm{K}-\mathrm{LVA}}$ model with fast activation $(w)$ and slow inactivation $(z)$ was based on whole-cell recordings from MSO cells. We described activation with the model by Mathews et al. (2010). Dynamics of $I_{\mathrm{K}-\mathrm{LVA}}$ inactivation in our recordings (P. Mathews and N. Golding, unpublished data) was fit well with a sum of two exponentials: for $-55,-50,-45$, and $-40 \mathrm{mV}$, the fast inactivation time constants (in $\mathrm{ms}$ ) are $35.4 \pm 42.8,71.7 \pm 5.1$, $56.1 \pm 3.2$, and $49.7 \pm 3.2$, and the slow time constants are $242.0 \pm 64.8$, $549.5 \pm 22.9,485.5 \pm 45.9$, and $479.5 \pm 33.6$, respectively. We described the $I_{\mathrm{K}-\mathrm{LVA}}$ inactivation time constants with the model from Rothman and Manis (2003a,b), which (when corrected for temperature) agreed well with our measurements. The current balance equation takes the following form:

$$
\begin{aligned}
& C_{\mathrm{m}} \frac{d V}{d t}=-g_{\mathrm{L}}\left(V-E_{\mathrm{L}}\right)-\bar{g}_{\mathrm{K}-\mathrm{LVA}} w^{4} z\left(V-E_{\mathrm{K}}\right)- \\
& \bar{g}_{\mathrm{h}}\left(k_{\mathrm{r}} r_{\mathrm{f}}+\left(1-k_{\mathrm{r}}\right) r_{\mathrm{s}}\right)\left(V-E_{\mathrm{h}}\right)+I(t),
\end{aligned}
$$

with capacitance $C_{\mathrm{m}}=25 \mathrm{pF}$, leak conductance $g_{\mathrm{L}}=15 \mathrm{nS}$, peak conductances $\bar{g}_{\mathrm{K}-\mathrm{LVA}}=190 \mathrm{nS}$ and $\bar{g}_{\mathrm{h}}=70 \mathrm{nS}$, reversal potentials $E_{\mathrm{L}}=$ $-77.5 \mathrm{mV}, E_{\mathrm{K}}=-106 \mathrm{mV}$, and $E_{\mathrm{h}}=-37 \mathrm{mV}, k_{\mathrm{r}}=0.65$, and external input $I(t)$. The cell had a resting membrane potential of $-58 \mathrm{mV}$. Most parameters were based on whole-cell measurements from MSO neurons, whereas the parameters for which we did not have direct experimental data $\left(\bar{g}_{\mathrm{K}-\mathrm{LVA}}, g_{\mathrm{L}}, E_{\mathrm{L}}\right)$ were set such that we could account for experimental measurements of the input resistance $R_{\mathrm{N}}(8.5 \mathrm{M} \Omega)$, membrane time constant $\tau_{\mathrm{m}}(0.34 \mathrm{~ms})$, and the resting membrane potential $V_{\text {rest }}(-58$ $\mathrm{mV}$ ) under control conditions and when $I_{\mathrm{h}}$ or $I_{\mathrm{K} \text {-LVA }}$ was blocked. Gating variables $w, z, r_{\mathrm{f}}$, and $r_{\mathrm{s}}$ evolve according to first-order differential equations $\tau_{x} \frac{\mathrm{dx}}{\mathrm{dt}}=\mathrm{x}_{\infty}(V)-x$ with steady-state activation or inactivation functions,

$$
w_{\infty}(V)=\frac{1}{1+\exp (-(V+57.3) / 11.7)}
$$




$$
\begin{gathered}
z_{\infty}(V)=0.22+\frac{0.78}{1+\exp ((V+57) / 5.44)} \\
r_{\infty}(V)=\frac{1}{1+\exp ((V+60.3) / 7.3)},
\end{gathered}
$$

and voltage-dependent time constants of the gating variables at $35^{\circ} \mathrm{C}$,

$$
\begin{aligned}
& \tau_{\mathrm{w}}(V)=0.46 \frac{100}{6 \exp ((V+75) / 12.15)+24 \exp (-(V+75) / 25)+0.55} \\
& \tau_{\mathrm{z}}(V)=0.24\left[\frac{1000}{\exp ((V+60) / 20)+\exp (-(V+60) / 8)}+50\right] \\
& \tau_{\mathrm{r}_{\mathrm{f}}}(V)=10^{4}\left[\frac{-7.4(V+60)}{\exp (-(V+60) / 0.8)-1}+65 \exp (-(V+56) / 23)\right]^{-1} \\
& \tau_{\mathrm{r}_{\mathrm{s}}}(V)=10^{6}\left[\frac{-56(V+59)}{\exp (-(V+59) / 0.8)-1}+\right.
\end{aligned}
$$

$$
0.24 \exp (-(V-68) / 16)]^{-1}
$$

Excitatory synaptic input was modeled by current injections with a time course described by an $\alpha$ function with a time constant of $0.6 \mathrm{~ms}$.

We computed the input resistance $R_{\mathrm{N}}(t)$ at $V(t)$ for short ( $\sim 10 \mathrm{~ms}$ ) current pulses by linearizing the current balance equation around the voltage $V(t)$. Because activation of $\mathrm{K}_{\mathrm{LVA}}$ is fast and $\mathrm{K}_{\mathrm{LVA}}$ inactivation and $I_{\mathrm{h}}$ activation are relatively slow $(\sim 100 \mathrm{~ms})$, we can write

$$
R_{\mathrm{N}}(t, V)=\frac{1}{g_{\mathrm{L}}+\bar{g}_{\mathrm{K}-\mathrm{LVA}} w_{\infty}^{4}(V) z(t)+\bar{g}_{\mathrm{h}} r(t)+g_{\mathrm{w}}(t, V)}
$$

with $r(t)=k_{r} r_{f}(t)+\left(1-k_{\mathrm{r}}\right) r_{\mathrm{s}}(t)$ and $g_{\mathrm{w}}(t, V)=4 \bar{g}_{\mathrm{K}-\mathrm{LVA}} w_{\infty}^{3}(V) z(t)(V-$ $\left.E_{\mathrm{K}}\right) w_{\infty}^{\prime}(V)$, where $w_{\infty}^{\prime}(V)$ is the derivative of the activation function $w_{\infty}(V)$ with respect to $V$ evaluated at $V$.

To predict the response to input transients that are superimposed on a slowly varying or DC input $I(t)$, we also computed the impedance $Z$ at time $t$ and voltage $V(t)$ for high-frequency sinusoids $(>100 \mathrm{~Hz})$. For such frequencies, the dynamics of $z(t), r_{\mathrm{f}}(t)$, and $r_{\mathrm{s}}(t)$ are too slow to contribute to the impedance, and we can write

$$
Z(t, V ; \omega)=\left[i \omega C_{\mathrm{m}}+g_{\mathrm{L}}+\bar{g}_{\mathrm{K}-\mathrm{LVA}} w_{\infty}^{4}(V) z(t)+\bar{g}_{\mathrm{h}} r(t)\right.
$$

$$
\left.+\frac{g_{\mathrm{w}}(t, V)}{1+i \omega \tau_{w}(V)}\right]^{-1}
$$

where $\omega=2 \pi f$ with frequency $f$. Taking the absolute value of this complex valued expression gives the impedance.

We also computed the afterhyperpolarization (AHP) that follows an EPSC train. We define the variable $V_{\text {aft }}$ at time $t$ as the voltage to which the cell model would immediately relax (within $\sim 10 \mathrm{~ms}$ ), if the input $I(t)$ ends at time $t$. To compute $V_{\text {aft }}(t)$ during a simulated EPSC train, we solved the implicit equation

$$
g_{\mathrm{L}}\left(V_{\mathrm{aft}}-E_{\mathrm{L}}\right)+\bar{g}_{\mathrm{K}-\mathrm{LVA}} w_{\infty}^{4}\left(V_{\mathrm{aft}}\right) z(t)\left(V_{\mathrm{aft}}-E_{\mathrm{K}}\right)+\bar{g}_{\mathrm{h}} r(t)\left(V_{\mathrm{aft}}-E_{\mathrm{h}}\right)=0 .
$$

Note that we consider that $\mathrm{K}_{\mathrm{LVA}}$ activation $w(t)$ reaches its steadystate value $w_{\infty}\left(V_{\text {aft }}\right)$ shortly (well within $\sim 10 \mathrm{~ms}$ ) after the stimulus has stopped, because it has a relatively fast time constant $(\sim 1 \mathrm{~ms})$. To compute the input resistance for $10 \mathrm{~ms}$ current pulses immediately after an input train (as we did in the experiments), the membrane potential $V(t)$ in the above equation for $R_{\mathrm{N}}(t)$ was replaced by $V_{\mathrm{aft}}(t)$.

We computed the initial and steady-state voltage after a step current input $I$ from $V_{\text {rest }}$. The instantaneous current-voltage relation was obtained by considering that the slow gating variables $z, r_{\mathrm{f}}$, and $r_{\mathrm{s}}$ are still at their resting values associated with $V_{\text {rest }}$, whereas the fast K-LVA activation has reached its equilibrium at the initial voltage $V_{\text {init }}$ :

$$
\begin{aligned}
I=g_{\mathrm{L}}\left(V_{\text {init }}-E_{\mathrm{L}}\right)+\bar{g}_{\mathrm{K}-\mathrm{LVA}} w_{\infty}^{4}\left(V_{\text {init }}\right) z_{\infty}\left(V_{\text {rest }}\right)\left(V_{\text {init }}-E_{\mathrm{K}}\right) \\
\\
+\bar{g}_{\mathrm{h}} r_{\infty}\left(\mathrm{V}_{\text {rest }}\right)\left(V_{\text {init }}-E_{\mathrm{h}}\right) .
\end{aligned}
$$

For the steady-state current-voltage relation, all gating variables were considered to be in equilibrium at the steady-state voltage $V_{\mathrm{ss}}$ :

$$
\begin{aligned}
I=g_{\mathrm{L}}\left(V_{\mathrm{ss}}-E_{\mathrm{L}}\right)+\bar{g}_{\mathrm{K}-\mathrm{LVA}} w_{\infty}^{4}\left(V_{\mathrm{ss}}\right) z_{\infty}\left(V_{\mathrm{ss}}\right)\left(V_{\mathrm{ss}}-E_{\mathrm{K}}\right) & \\
& +\bar{g}_{\mathrm{h}} r_{\infty}\left(\mathrm{V}_{\mathrm{ss}}\right)\left(V_{\mathrm{ss}}-E_{\mathrm{h}}\right) .
\end{aligned}
$$

To compute spike probabilities, the dendro-somatic compartment model described above was extended with an axonal compartment that included action-potential-generating currents, a sodium current $\left(I_{\mathrm{Na}}\right)$, and a high-voltage-activated potassium current $\left(I_{\mathrm{K}-\mathrm{HVA}}\right)$, taken from Rothman and Manis (2003a,b). The axonal compartment had a capacitance $C_{\mathrm{m}}=12 \mathrm{pF}$, leak conductance $g_{\mathrm{L}}=24 \mathrm{nS}$, peak conductances $\bar{g}_{\mathrm{Na}}=3000 \mathrm{nS}$ and $\bar{g}_{\mathrm{K}-\mathrm{HVA}}=150 \mathrm{nS}$, and reversal potentials $E_{\mathrm{L}}=-58 \mathrm{mV}, E_{\mathrm{Na}}=55 \mathrm{mV}$, and $E_{\mathrm{K}}=-106 \mathrm{mV}$. The (in)activation time constants of the active currents were adjusted for a temperature of $35^{\circ} \mathrm{C}$. The somatic and axonal voltages were coupled via an axial conductance $g_{\text {axial }}=50 \mathrm{nS}$, reproducing the strong attenuation of action potentials from the axon to the soma (Scott et al., 2007). A noise current was added to the somatic compartment, consisting of white Gaussian noise that was low-pass filtered with time constant of $0.2 \mathrm{~ms}$, giving the noise current an $\mathrm{SD}$ of $\sim 167 \mathrm{pA}$.

\section{Results}

$I_{\mathrm{h}}$ and $I_{\mathrm{K}-\mathrm{LVA}}$ are key determinants of the resting properties of MSO principal cells

We examined the electrophysiological properties of 212 principal neurons of the MSO. Principal neurons were readily distinguishable in current-clamp recordings based on criteria established in previous in vitro patch-clamp studies (Svirskis et al., 2002; Scott et al., 2005), including the bipolar morphology of their dendrites as viewed under IR-DIC optics, the display of strong outward rectification in the voltage range above the resting potential, and the initiation of a single small $(<25 \mathrm{mV})$ action potential in response to all suprathreshold current stimuli (Fig. $1 A$ ). MSO principal neurons consistently exhibited low input resistances $(<19$ $\mathrm{M} \Omega$; average, $8.2 \pm 0.6 \mathrm{M} \Omega ; n=9$ ) as was apparent in the voltage-current relationship (Fig. $1 A, D$ ). The membrane time constant of MSO neurons was $<0.4 \mathrm{~ms}$ on average (Fig. $1 C$ ). The resting membrane properties were strongly determined by the dual influence of hyperpolarization-activated cationic current $\left(I_{\mathrm{h}}\right)$ as well as low-voltage-activated $\mathrm{K}^{+}$current $\left(I_{\mathrm{K}-\mathrm{LVA}}\right)$. Blockade of h-channels with either $50 \mu \mathrm{M}$ extracellular ZD7288 or 10 $\mathrm{mm}$ cesium hyperpolarized the resting potential by $13 \pm 3 \mathrm{mV}$ $(n=6)$ and $14 \pm 4.8 \mathrm{mV}(n=5)$, respectively, abolished the delayed, depolarizing sag during hyperpolarizing current injections and increased the input resistance and membrane time constant threefold (Fig. $1 B-F$ ). Similar results were obtained when h-channels were blocked internally with the inclusion of $20 \mu \mathrm{M}$ ZD7288 in the pipette solution $\left(R_{\mathrm{N}}=21 \pm 3.2 \mathrm{M} \Omega\right.$ for internal vs $24.9 \pm 5.8 \mathrm{M} \Omega$ for external ZD7288; $p>0.5 ; n=6$ for both groups). $I_{\mathrm{K}-\mathrm{LVA}}$ also contributed to the resting properties of MSO neurons. Blockade of $\mathrm{K}_{\mathrm{v}} 1$.1-containing channels with bath application of $80 \mathrm{~nm}$ dendrotoxin $\mathrm{K}$ (DTX-K) resulted in a twofold to threefold increase in input resistance and membrane time constant but only produced a slight depolarization of the resting potential (Fig. $1 B-F$ ), consistent with previous studies (Scott et al., 2005, 2007; Mathews et al., 2010). Together, these results indicate that $I_{\mathrm{h}}$ and $I_{\mathrm{K}-\mathrm{LVA}}$ are active at the resting potential and allow for rapid membrane voltage changes via their powerful contributions to the large membrane conductance of MSO principal neurons. 


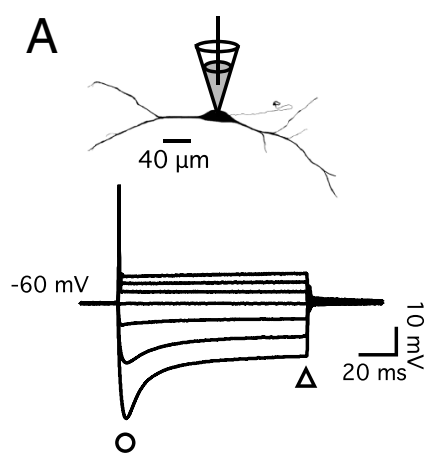

D

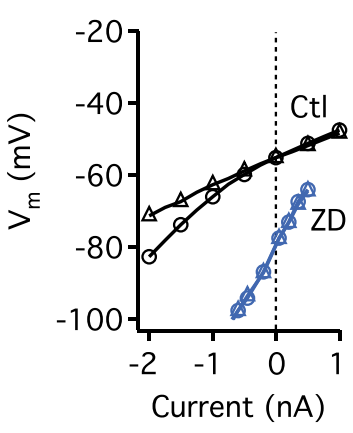

B
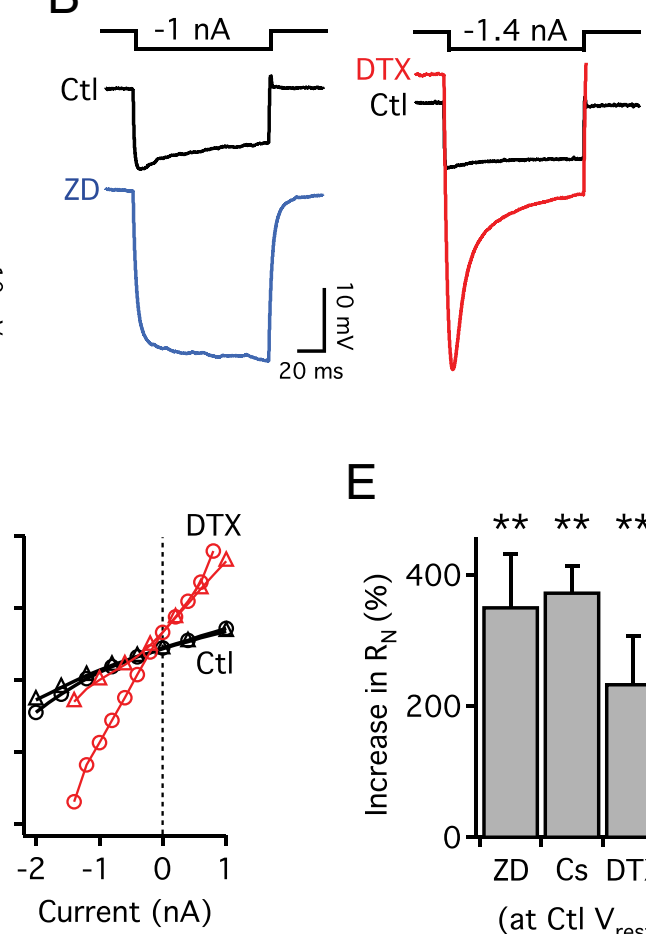

$E$

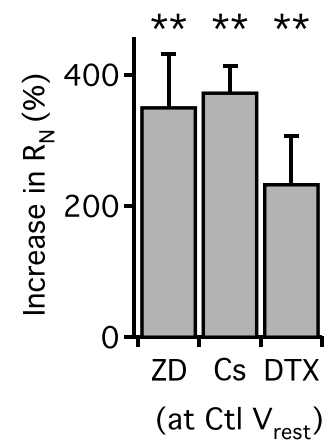

C

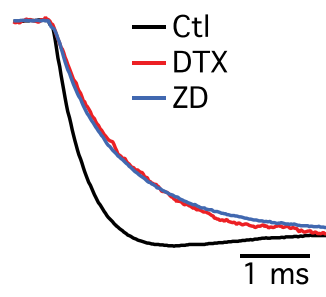

$\mathrm{F}$

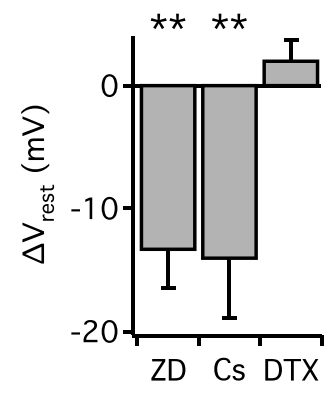

Figure 1. $I_{\mathrm{h}}$ and $I_{\mathrm{K}-\mathrm{LVA}}$ determine the membrane properties of MSO neurons. $A$, The bipolar neurons of MSO (top) fire phasically (bottom) in response to depolarizing square current pulses. Peak input resistance is measured for hyperpolarizing square current injection at the time indicated by the open circle, whereas steady-state input resistance is measured at the time indicated by the open triangle. $\boldsymbol{B}$, Application of an $I_{\mathrm{h}}$ blocker (50 $\mu \mathrm{m}$ ZD7288) results in membrane hyperpolarization, an increase of input resistance, and block of sag in hyperpolarization. Application of $80 \mathrm{~nm}$ DTX-K, a selective blocker of $K_{v} 1.1$, depolarizes the membrane and increases input resistance. $C$, MSO neurons have fast membrane time constants, which are prolonged as a result of blocking $I_{\mathrm{K}-\mathrm{LVA}}$ or $I_{\mathrm{h}}$. The traces are average of responses of different cells normalized to $1 \mathrm{mV}(n=12 \mathrm{for}$ control, $n=7 \mathrm{for} Z \mathrm{DD} 288, n=6 \mathrm{for} \mathrm{DTX}$-K). Time constants for the control (CtI), DTX-K (DTX), and ZD7288 (ZD) are $0.38 \pm 0.005,1.03 \pm 0.006$, and $0.93 \pm 0.005$ ms, respectively. D, Voltage- current relationship of MSO neurons in control and $I_{K-L V A}$ and $I_{h}$ blocked conditions. In the presence of ZD7288, the cell hyperpolarizes and the input resistance increases significantly. In the presence of DTX-K, there is a similar increase in input resistance. $\boldsymbol{E}$, In MSO neurons, the steady-state input resistance increases strongly when $I_{\mathrm{h}}\left(50 \mu \mathrm{M} Z \mathrm{ZD7288}, n=6 ; 10 \mathrm{~mm}(\mathrm{~s}, n=5)\right.$ or $I_{\mathrm{K}-\mathrm{LVA}}(80 \mathrm{~nm}$ DTX-K, $n=6)$ are blocked. $\boldsymbol{F}$, The resting membrane potential of MSO neurons is hyperpolarized when $I_{\mathrm{h}}$ is blocked and depolarized when $I_{\mathrm{K}-\mathrm{LVA}}$ is blocked. $I_{\mathrm{h}}$ is blocked by $50 \mu \mathrm{M} Z \mathrm{ZD} 288$ ( $n=6$ ) or $10 \mathrm{mM}$ $\mathrm{Cs}(n=5)$, and $I_{\mathrm{K}-\mathrm{LVA}}$ is blocked by $80 \mathrm{nM}$ DTX-K $(n=6) .{ }^{* *} p<0.01$.

\section{Dynamics of $I_{\mathrm{h}}$ and $I_{\mathrm{K}-\mathrm{LVA}}$ during EPSP trains}

Given that $I_{\mathrm{h}}$ and $I_{\mathrm{K} \text {-LVA }}$ are partially activated at rest, we asked whether their respective contributions varied during the kinds of repetitive synaptic stimuli typically encountered by MSO neurons during acoustic activity. Voltage-dependent changes in $I_{\mathrm{h}}$ activation and $I_{\mathrm{K}-\mathrm{LVA}}$ activation and inactivation during trains of synaptic activity could powerfully influence resting membrane properties. Although the brief duration of individual EPSPs in MSO neurons $(\sim 1-2 \mathrm{~ms})$ would not be expected to provide substantial changes in $I_{\mathrm{h}}$ activation or $I_{\mathrm{K}-\mathrm{LVA}}$ inactivation, both operating on a timescale of $\sim 100 \mathrm{~ms}$, such changes might accumulate during repetitive synaptic activity. To examine this, we made whole-cell recordings from MSO neurons and determined changes in $I_{\mathrm{h}}$ or $I_{\mathrm{K}-\mathrm{LVA}}$ during trains of simulated EPSPs in voltage clamp (sEPSPs, 3-15 mV, delivered at $500 \mathrm{~Hz}$ from a holding potential of $-60 \mathrm{mV})$. This frequency $(500 \mathrm{~Hz})$ was chosen because it approximates the upper range in which bushy cells, which provide excitatory inputs to the MSO, show reliable entrainment (Joris et al., 1994).

For recordings in which $I_{\mathrm{h}}$ was isolated pharmacologically (see Materials and Methods), EPSP trains elicited not only the corresponding and expected leak and capacitive currents but also a slowly developing outward current that outlasted the time course of the stimulus for hundreds of milliseconds (Fig. 2A, left traces and black arrows). The slow outward current was monotonically related to the amplitude of the EPSP voltage commands. In the presence of $50 \mu \mathrm{M} Z \mathrm{ZD} 7288$, the resting conductance was reduced and the slow outward current was essentially $(>91 \%)$ blocked (Fig. $2 A$, middle). These results indicate that $I_{\mathrm{h}}$ contributes to the resting conductance at $-60 \mathrm{mV}$ and that a proportion of this current deactivates during trains of depolarizations. To quantify the proportion of $I_{\mathrm{h}}$ deactivation, we performed a tail current analysis at $-100 \mathrm{mV}$ and found that up to $40 \%$ of $g_{\mathrm{h}}$ deactivated during a $15 \mathrm{mV}$ EPSP train relative to the resting conductance at $-60 \mathrm{mV}$ (Fig. $2 \mathrm{~B}$ ).

A tail current analysis comparable with that used to describe $I_{\mathrm{h}}$ deactivation (Fig. $2 A, B$ ) could not be used during $I_{\mathrm{K}-\mathrm{LVA}}$ inactivation because of the technical difficulties of accurately subtracting capacitive currents in whole-cell voltage-clamp recordings. When pharmacologically isolating $I_{\mathrm{K}-\mathrm{LVA}}$ (see Materials and Methods), we observed a slowly developing reduction in $I_{\mathrm{K}-\mathrm{LVA}}$ during trains of EPSP stimuli, reflecting a cumulative inactivation (Fig. $2 C$, Control). Because $I_{\mathrm{K}-\mathrm{LVA}}$ is partially activated at $-60 \mathrm{mV}$, the percentage of $I_{\mathrm{K}-\mathrm{LVA}}$ inactivation as a fraction of total $I_{\mathrm{K}-\mathrm{LVA}}$ cannot be measured. Thus, we measured the percentage of $I_{\mathrm{K}-\mathrm{LVA}}$ inactivation as a fraction of $I_{\mathrm{K}-\mathrm{LVA}}$ activated as a result of the stimulus train (Fig. $2 D$ ). Up to $15 \%$ of $I_{\mathrm{K}-\mathrm{LVA}}$ undergoes inactivation for a $15 \mathrm{mV}$ sEPSP train.

To gain insight into the subthreshold dynamics of the active membrane properties during EPSP trains, we constructed a single-compartment MSO cell model containing the three major channel types that operate in the subthreshold voltage regimen: 
$I_{\mathrm{h}}, I_{\mathrm{K}-\mathrm{LVA}}$, and a passive leak current $\left(I_{\mathrm{L}}\right)$ (see Materials and Methods). The voltage response during $500 \mathrm{~Hz}$ EPSC trains (Fig. $3 A)$ is similar to our experimental current-clamp recordings, which are discussed below (see Figs. 4A, 7A). $I_{\mathrm{K}-\mathrm{LVA}}$ exhibits rapid activation and deactivation with each cycle of the stimulus, along with a tonic activation after the stimulus onset (Fig. 3B, red trace). Additionally, a progressive inactivation of $I_{\mathrm{K}-\mathrm{LVA}}$ and deactivation of $I_{\mathrm{h}}$ occurs on a timescale of tens to hundreds of milliseconds (Fig. 3B, magenta and blue traces). These dynamics are reflected in the conductances $g_{\mathrm{K}-\mathrm{LVA}}$ and $g_{\mathrm{h}}$. Because of the slow inactivation of $I_{\mathrm{K} \text {-LVA }}$, the envelope of $g_{\mathrm{K} \text {-LVA }}$ exhibits a gradual decline (Fig. 3C, red trace). In addition, $g_{\mathrm{h}}$ undergoes gradual reduction, without being affected by individual EPSPs attributable to the slow $I_{\mathrm{h}}$ kinetics (Fig. 3C, blue trace). The overall membrane conductance $\left(G_{\mathrm{m}}=g_{\mathrm{K} \text {-LVA }}+g_{\text {leak }}\right.$ $\left.+g_{\mathrm{h}}\right)$ initially increases with stimulus onset but soon declines below prestimulus state as a result of the cumulative inactivation of $I_{\mathrm{K}-\mathrm{LVA}}$ and deactivation of $I_{\mathrm{h}}$ (Fig. $3 C$, black trace). This decline in membrane conductance persists long after the stimulus offset. The cumulative changes in the gating of the two currents are also manifested in the envelopes of the currents (Fig. $3 D$ ). The cumulative components of the two currents counteract one another and result in a fluctuating summed outward current that shows little cumulative change over the entire time course of the train (Fig. $3 D$, light blue trace). The similar time course of recovery from inactivation of $I_{\mathrm{K}-\mathrm{LVA}}$ and from deactivation of $I_{\mathrm{h}}$ results in a constant total current at the end of the stimulus (Fig. $3 D$, arrow).

\section{Cumulative effects of $I_{\mathrm{h}}$ deactivation and $I_{\mathrm{K}-\mathrm{LVA}}$ inactivation on MSO responses}

From the cumulative changes in the conductance of the model (Fig. 3C), one would expect that the input resistance of MSO neurons is increased at the end of the stimulus. Stimulus-induced changes in membrane sensitivity were assessed by probing the input resistance $150 \mathrm{~ms}$ before and $10 \mathrm{~ms}$ after a train of sEPSCs in somatic current-clamp recordings (Fig. 4A). A 1 s $500 \mathrm{~Hz}$ train of $9 \mathrm{mV}$ EPSPs in this example resulted in $28 \%$ increase in input resistance. To understand what aspects of the stimulus train were critical for regulating membrane input resistance, we manipulated stimulus frequency and amplitude independently of one another (Fig. 4 B). In one set of experiments, peak EPSP depolarization and train duration were kept constant (uniform EPSC train, $9 \mathrm{mV}, 1 \mathrm{~s}$ ), and stimulus frequency was varied from 100 to $500 \mathrm{~Hz}(n=5)$. A $6 \%$ increase in input resistance was detected at $100 \mathrm{~Hz}$, and these changes increased linearly with frequency up to $23.7 \%$, at a rate of $4.5 \% / 100 \mathrm{~Hz}$ (Fig. $4 B$, top). Alternately, EPSP amplitude was varied while the frequency and duration of the sEPSC train were held constant $(500 \mathrm{~Hz}, 1 \mathrm{~s}, n=8)$. The increase in input resistance varied linearly with EPSP amplitude, up to $60 \%$ with $15 \mathrm{mV}$ sEPSPs (Fig. $4 B$, bottom).
Despite significant $I_{\mathrm{h}}$ deactivation and $I_{\mathrm{K}-\mathrm{LVA}}$ inactivation, we found that the membrane potential returned quickly to its prestimulus value, only showing a very small AHP (Fig. $4 C$, top). The AHP after trains of $15 \mathrm{mV}$ EPSPs was $<1 \mathrm{mV}$ for stimulus frequencies of up to $500 \mathrm{~Hz}(n=5)$ (Fig. $4 C$, bottom). The fast return to rest is explained by the similar time course of $I_{\mathrm{K}-\mathrm{LVA}}$ and $I_{\mathrm{h}}$ after EPSC trains, essentially cancelling their respective hyperpolarizing and depolarizing effects (Fig. $3 D$ ). The small, short AHP primarily reflects the rapid deactivation of $I_{\mathrm{K}-\mathrm{LVA}}$ activated during the stimulus.

The time course of development and duration of input resistance increases was consistent with the slow kinetics of $I_{\mathrm{K}-\mathrm{LVA}}$ inactivation and $I_{\mathrm{h}}$ deactivation in MSO principal neurons. To observe the time course over which input resistance changes develop, we delivered sEPSC trains of uniform amplitude and frequency (adjusted to elicit 8-10 mV EPSPs at either 250 or 500 $\mathrm{Hz}$ ) and varied train duration from $10 \mathrm{~ms}$ to $2 \mathrm{~s}$ (Fig. $4 D$, inset). The increase in input resistance of MSO principal neurons could be fit well with a dual-exponential function (Fig. 4D). For $500 \mathrm{~Hz}$ sEPSC trains, fast and slow time constants averaged $45.1 \pm 10.1$ and $915.9 \pm 215 \mathrm{~ms}$, respectively, whereas for a $250 \mathrm{~Hz}$ train, time constants approximately doubled to $74.8 \pm 34.7$ and $1642.3 \pm$ $1940 \mathrm{~ms}$. Once initiated, input resistance changes were long lasting. The time course of input resistance decay was assessed using either a $200 \mathrm{~ms}$ or $2 \mathrm{~s}$ stimulus train $(9 \mathrm{mV}$ EPSPs at $500 \mathrm{~Hz}$ ) (Fig. $4 E)$. As with the development of the increase in input resistance, 

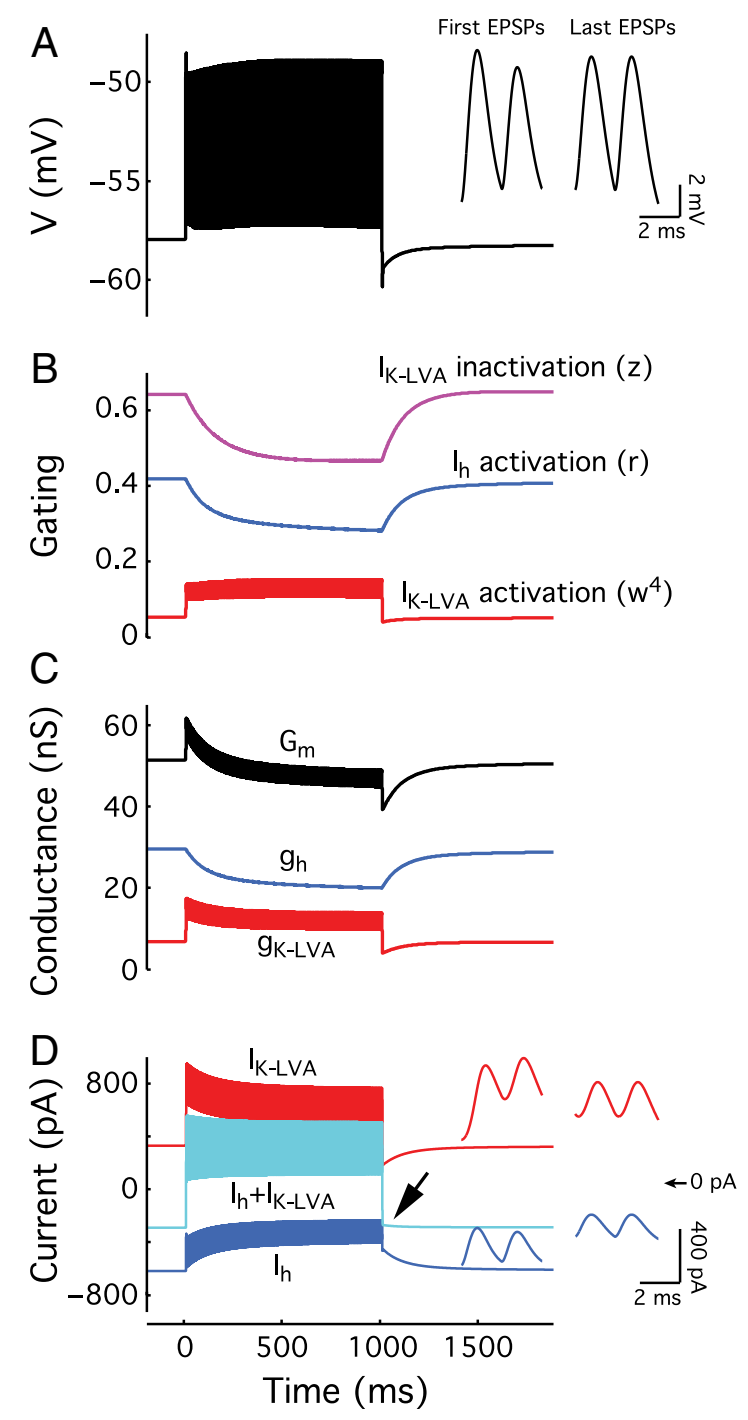

Figure 3. Model illustrates cumulative deactivation of $I_{\mathrm{h}}$ and inactivation of $I_{\mathrm{K}-\mathrm{LVA}}$ during EPSC train and its resulting decrease of the total membrane conductance $G_{\mathrm{m}}$. Model input consists of $1 \mathrm{~s}, 500 \mathrm{~Hz}$ EPSC trains with $850 \mathrm{pA}$ peak amplitude. $\boldsymbol{A}$, Membrane potential (black curve). Inset, Zooms of the first and the last two EPSPs. $\boldsymbol{B}$, Gating variables: $I_{\text {K-LVA }}$ activation (red), $I_{\text {K-LVA }}$ inactivation (magenta), and $I_{\mathrm{h}}$ activation (blue). $C$, Conductances of individual ionic currents $g_{\mathrm{K}-\mathrm{LVA}}($ red $), g_{\mathrm{h}}$ (blue), and the total membrane conductance (including the leak conductance $g_{\text {leak }}$ ) $G_{m}$ (black). $D$, lonic currents $I_{K-L V A}$ (red) and $I_{\mathrm{h}}$ (blue) and their sum $I_{\mathrm{h}}+I_{\mathrm{K} \text {-LVA }}$ (light blue). Inset, Zooms of current traces during first and last two EPSPs.

the decay of input resistance followed a dual-exponential time course. The decay of input resistance from the $200 \mathrm{~ms}$ train was significantly more rapid than for the $2000 \mathrm{~ms}$ train (for $200 \mathrm{~ms}$, $\tau_{\text {fast }}=24.1 \pm 5.4 \mathrm{~ms}, \tau_{\text {slow }}=231.5 \pm 57.3 \mathrm{~ms}$; for $2000 \mathrm{~ms}, \tau_{\text {fast }}=$ $36.6 \pm 1.9 \mathrm{~ms}, \tau_{\text {slow }}=440.9 \pm 28.7 \mathrm{~ms}$ ).

To probe the interactions between $I_{\mathrm{h}}$ and $I_{\mathrm{K}-\mathrm{LVA}}$ during EPSP trains, we examined the effects of their respective blockers $(50 \mu \mathrm{M}$ ZD7288 and $80 \mu \mathrm{M}$ DTX-K) on the integration of sEPSC trains (Fig. $4 F$ ). In the presence of ZD7288, EPSP responses showed more temporal summation, and cumulative changes in input resistance were sharply reduced (Fig. $4 F, G ; R_{\mathrm{N}}$ measured as in Fig. $4 A$ ). In contrast, when $I_{\mathrm{K}-\mathrm{LVA}}$ was blocked by DTX-K, initial EPSPs summated briefly before the emergence of a cumulative hyperpolarization, culminating in a large AHP after train offset (Fig. $4 F, H$ ). This effect was presumably attributable to the cumulative deactivation of $I_{\mathrm{h}}$ in the absence of a counterbalancing depolarization mediated by $I_{\mathrm{K}-\mathrm{LVA}}$ inactivation. DTX-K also reduced but did not eliminate the increase in input resistance (Fig. $4 F, G)$. In ZD7288, the cumulative depolarization resulting from $I_{\mathrm{K}-\mathrm{LVA}}$ inactivation is likely to be partially masked by the fact that greater temporal summation of EPSPs induces greater $I_{\mathrm{K}-\mathrm{LVA}}$ activation.

\section{Contribution of $I_{\mathrm{h}}$ deactivation and $I_{\mathrm{K}-\mathrm{LVA}}$ inactivation to input resistance changes}

On the basis of the pharmacological experiments (Fig. $4 \mathrm{~F}-\mathrm{H}$ ), one may be tempted to assign fractional contributions of $I_{\mathrm{h}}$ and $I_{\mathrm{K}-\mathrm{LVA}}$ to the cumulative input resistance increases. However, it is important to consider the conditions under which input resistance is measured in assessing how both currents contribute to cumulative changes in $R_{\mathrm{N}}$. In experiments, we measured $R_{\mathrm{N}}$ at the membrane potential after halting the EPSC train at various time points (Fig. 4). Using our single-compartment model, we can display the evolution of this after-train potential $V_{\text {aft }}$ during the response to an EPSC train (Fig. $5 A$, green trace in top left) and compute the buildup and decay of $R_{\mathrm{N}}$ at this potential (Fig. $5 A$, solid black line in bottom left), revealing a similar magnitude and time course of $R_{\mathrm{N}}$ increases as in the experiments (compare with Fig. $4 D, E$ ). Measurements of $R_{\mathrm{N}}$ during the natural afterhyperpolarization of the model cell exceeded measurements made at the resting potential of $-58 \mathrm{mV}$ ( $V_{\text {rest }}$, dashed black line), revealing the sensitivity of $R_{\mathrm{N}}$ measurements to the conditions under which they are made. The difference, in this comparison, reflects the steep voltage dependence of $I_{\mathrm{K}-\mathrm{LVA}}$ near rest, as well as the fast kinetics of its deactivation during the AHP. Under conditions of drug application, the membrane may depolarize or hyperpolarize abnormally and standardization of $R_{\mathrm{N}}$ measurement is especially meaningful. When blockade of $I_{\mathrm{h}}$ was simulated (Fig. 5A, middle), EPSP trains showed a gradual temporal summation, and $V_{\text {aft }}$ progressively depolarized (green line). In this condition, only a small (12\%) change in $R_{\mathrm{N}}$ occurred (solid red line), in agreement with the experimental results in Figure 4, $F$ and $G$. However, when the effects of the depolarizing $V_{\text {aft }}$ are compensated by measuring $R_{\mathrm{N}}$ at $V_{\text {rest }}$ (dashed red line), the input resistance increase was $36 \%$, reflecting the fact that increased activation of $I_{\mathrm{K}-\mathrm{LVA}}$ at $V_{\text {aft }}$ after the EPSP train masked the $R_{\mathrm{N}}$ change resulting from the cumulative inactivation of $I_{\mathrm{K}-\mathrm{LVA}}$ (Fig. $5 A-C$ ). Finally, when $I_{\mathrm{K}-\mathrm{LVA}}$ blockade was simulated, temporal summation of EPSPs was countered by a slow hyperpolarization also reflected in a slowly developing $V_{\text {aft }}$ (Fig. $5 \mathrm{~A}$, right). In this case, the strong increase in $R_{\mathrm{N}}$ (blue line) was mediated by the deactivation of $I_{\mathrm{h}}$. Although measurements of $R_{\mathrm{N}}$ during the afterhyperpolarization of the model suggest that $I_{\mathrm{h}}$ deactivation makes the strongest contribution to changes in $R_{\mathrm{N}}$ (Fig. $5 B$ ), when input resistance was calculated at the standardized membrane potential, $V_{\text {rest }}$, it is apparent that both $I_{\mathrm{h}}$ deactivation and $I_{\mathrm{K}-\mathrm{LVA}}$ inactivation contribute to cumulative changes in input resistance (Fig. 5C).

\section{Cumulative changes in membrane conductance are insensitive to fine stimulus statistics}

Our results demonstrate that an increase in membrane sensitivity during trains develops cumulatively and persists on a timescale of tens to hundreds of milliseconds. To assess the sensitivity of these changes to variable temporal patterns, we constructed trains of brief depolarizations of identical average frequency but differing in their degree of regularity. These trains ( $0.5 \mathrm{~ms}$ step pulses, 350 $\mathrm{Hz}$ average frequency, $1 \mathrm{~s}$ total duration) were constructed with interspike intervals (ISIs) that randomly varied according to a 

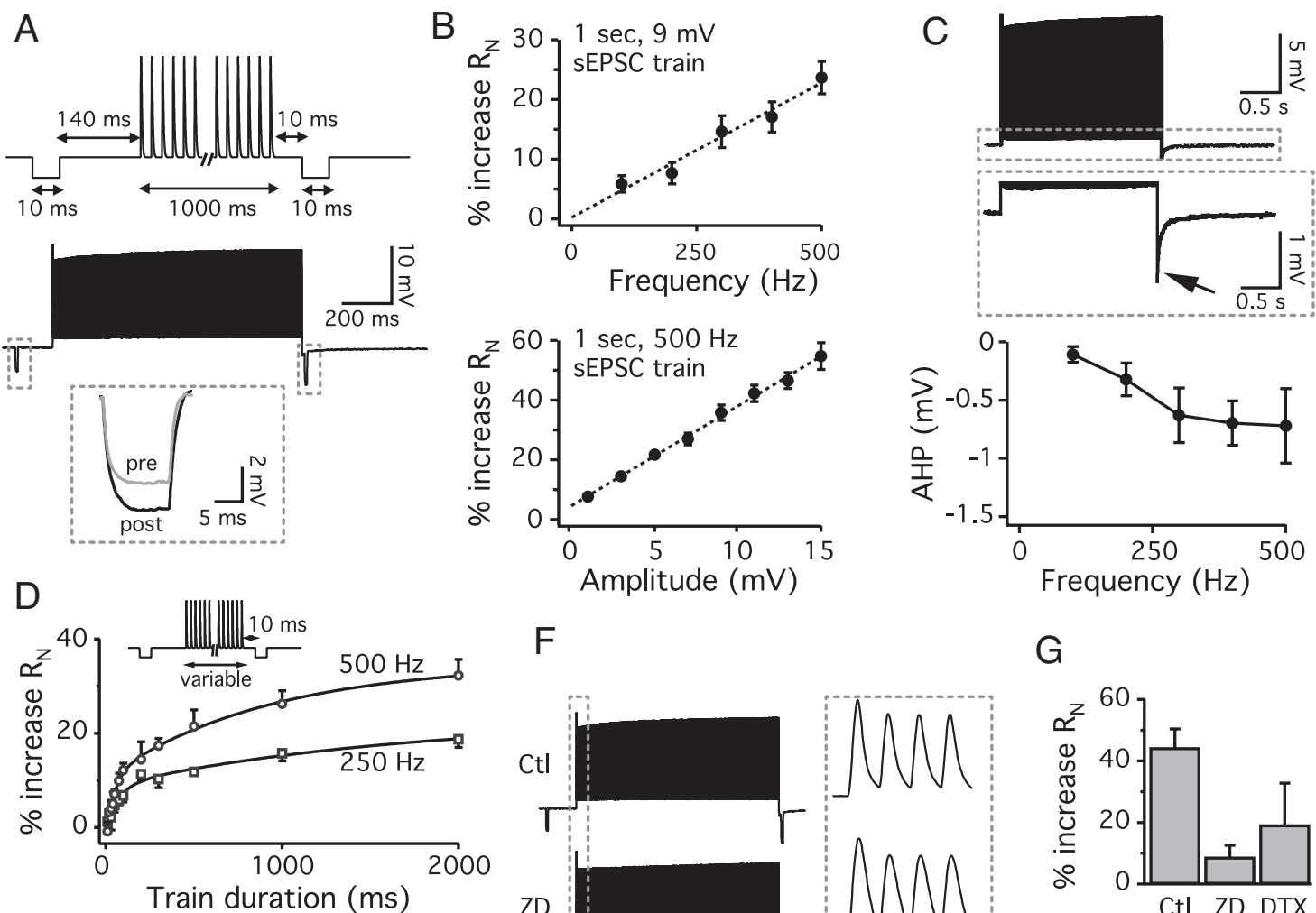

$\mathrm{G}$

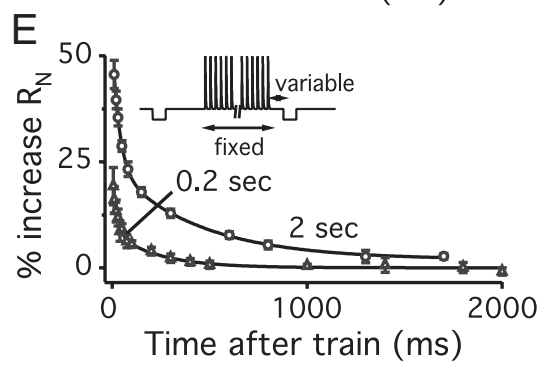

$\mathrm{F}$

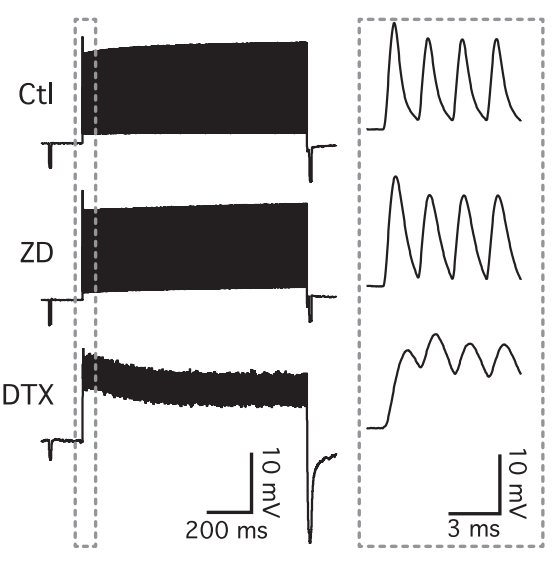

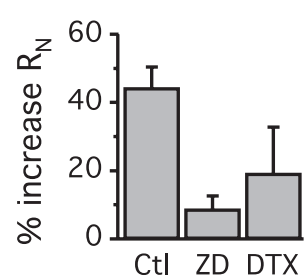

$\mathrm{H}$

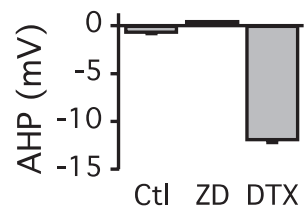

Figure 4. Trains of simulated synaptic stimuli trigger increase in input resistance, which accumulates and decays slowly as a function of frequency and amplitude of the input train. $A$, Top (schematic), Input resistance was probed $150 \mathrm{~ms}$ before and $10 \mathrm{~ms}$ after a $1 \mathrm{~s}, 500 \mathrm{~Hz}$ train of sEPSCs using short hyperpolarizing test pulses (10 ms duration, $-300 \mathrm{pA}$ amplitude). EPSC amplitude was adjusted to produce EPSPs of $\sim 9 \mathrm{mV}$. Voltage responses to the input resistance probes exhibit increases in amplitude as a result of the trains of sEPSCs (middle). Expanded view of prestimulus and poststimulus input resistance measurements produced a $28 \%$ increase in input resistance in this example. $\boldsymbol{B}$, Input resistance changes are linearly related to both frequency and amplitude of EPSP trains. Top, $R_{N}$ changes induced by a train of $9 \mathrm{mV}$ EPSPs of varying frequency. Linear fit (dotted line), $4.5 \% / 100 \mathrm{~Hz}$. Bottom, $R_{N}$ changes induced by a $500 \mathrm{~Hz}$ train of variable amplitude. Linear fit (dotted line), $4.6 \% / \mathrm{mV}$. There is significant variation across cells for the increase in input resistance. Because the data for change of input resistance as a function of frequency and amplitude were obtained from different cells, the increase in input resistance for comparable frequency and amplitude in $\boldsymbol{B}$ are somewhat different. $\boldsymbol{C}$, Long trains resulted in an AHP at the end of trains (top). The AHP was $<1 \mathrm{mV}(n=5)$ for trains up to $500 \mathrm{~Hz}$ (bottom). D. The increase in input resistance is gradual and biexponential. Subthreshold EPSP trains of $9 \mathrm{mV}$ were delivered at either $500 \mathrm{~Hz}$ (open circles, $n=5$ ) or $250 \mathrm{~Hz}$ (open squares, $n=4$ ) and varied in duration between 10 and $2000 \mathrm{~ms}$ (schematic: dotted inset). Input resistance was measured $10 \mathrm{~ms}$ after the train. Time constants for $500 \mathrm{~Hz}$ train are $45.1 \pm 10.1$ and $915.9 \pm 215 \mathrm{~ms}$ and for $250 \mathrm{~Hz}$ train are $74.8 \pm 34.7$ and $1642.3 \pm 1940 \mathrm{~ms}$, respectively. $E$, The input resistance changes last for hundreds of milliseconds. Subthreshold $500 \mathrm{~Hz}$ EPSP trains of $9 \mathrm{mV}$ were delivered for either $2000 \mathrm{~ms}$ (open circles, $n=9$ ) or $200 \mathrm{~ms}$ (open squares, $n=5$ ), whereas the posttrain input resistance was measured at varying intervals after train (schematic: dotted inset). The time constants of the decay of the input resistance increase for $200 \mathrm{~ms}$ train are $24.1 \pm 5.4$ and $231.5 \pm 57.3 \mathrm{~ms}$, whereas for $2000 \mathrm{~ms}$ train they are $36.6 \pm 1.9$ and $440.9 \pm 28.7 \mathrm{~ms}$. $\boldsymbol{F}$, Voltage responses of trains (left) in normal ACSF [control (Ct)): top], $I_{\mathrm{h}}$ block (middle) in the presence of $50 \mu \mathrm{m} \mathrm{ZD7288} \mathrm{(ZD),} \mathrm{and} \mathrm{I} \mathrm{K-LVA} \mathrm{block} \mathrm{[80} \mathrm{nM} \mathrm{DTX-K}$ (DTX)]. Right traces, Expanded view of first four responses for control, ZD7288, and DTX-K conditions. $\mathbf{G}, \boldsymbol{H}$, Summary of group data showing the sensitivity of input resistance changes (G) and AHP $(\boldsymbol{H})$ in control, $I_{\mathrm{h}}(n=6)$, and $I_{\mathrm{K}-\mathrm{LVA}}$ blockers $(n=9)$.

Gaussian distribution with an $\mathrm{SD}$ of $0,0.5,1.0,1.5$, or $2.0 \mathrm{~ms}$ (Fig. $6 \mathrm{~A})$. Ten random train patterns exhibiting each distribution of ISIs were generated and delivered to MSO principal cells in current-clamp mode, and input resistance changes were determined as in Figure $4 A$. In these experiments, stimulus intensity was adjusted to elicit action potentials, which increased the average membrane depolarization and improved the ability to discriminate stimulus-dependent changes in input resistance. In each cell, neither the mean nor the variance of the input resistance changes was altered by decreases in the regularity of the input trains (Fig. 6B,C) (no statistically significant difference across different SD conditions; $p>0.6$, ANOVA). For this analysis, the SDs of the input resistance measurements of different patterns for each cell were normalized to the respective mean values (coefficient of variation). If $I_{\mathrm{h}}$ deactivation or $I_{\mathrm{K}-\mathrm{LVA}}$ inactivation is sensitive to the short-term temporal structure of the input train, then there should be a systematic increase in the variance of the input resistance measurements with increasing values of ISI SDs. However, no systematic differences were observed in the five cells tested, with the mean $\mathrm{SD}$ of increase in input resistance ranging from 3.3 to $4.0 \%$ across the different conditions of stimulus regularity (Fig. $6 D$ ). These experiments thus show that changes in membrane sensitivity 
A
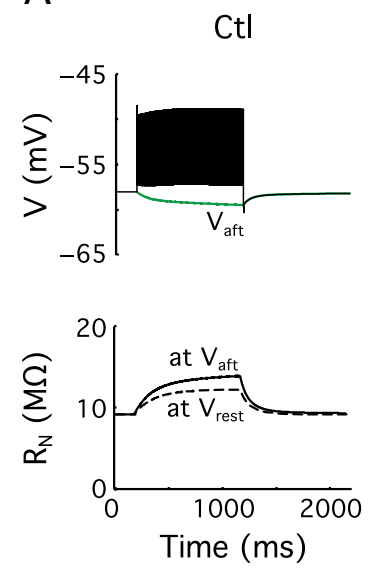

$\bar{g}_{h}=0($ (“D”)
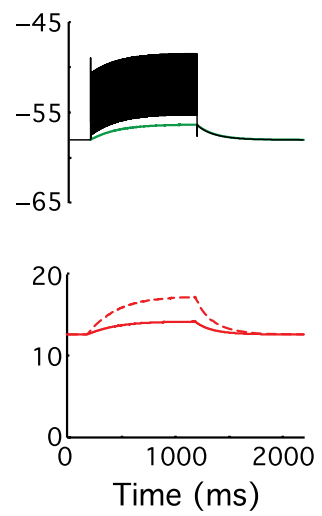
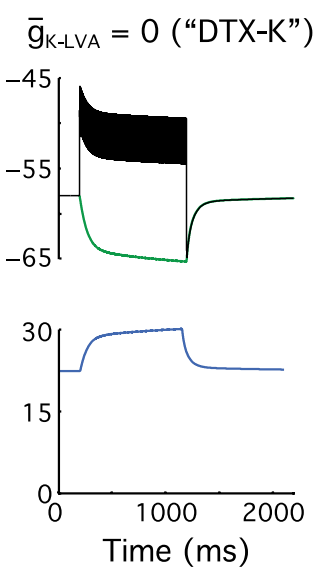

$\mathrm{B}$

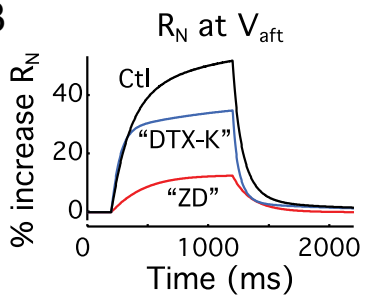

C

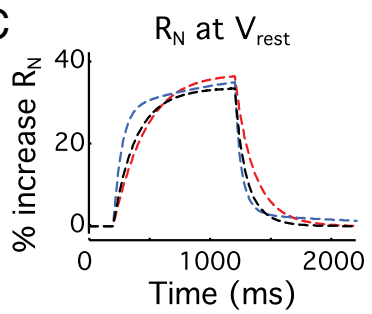

Figure 5. Simulations showing buildup and decay of input resistance $R_{\mathrm{N}}$ during and after EPSC trains under control conditions, $I_{\mathrm{h}}$ block, or $I_{\mathrm{K}-\mathrm{LVA}}$ block. $A$, Top, Membrane potential (black) and instantaneous resting potential $V_{\text {aft }}$ (green; see Materials and Methods) during $500 \mathrm{~Hz}$ EPSC train under control (Ctl), $I_{\mathrm{h}}$ block ("ZD"), and $I_{\mathrm{K}-\mathrm{LVA}}$ block ("DTX- $\left.\mathrm{K}^{\prime \prime}\right)$. As in the experiments, $V_{\text {rest }}$ is restored to control values $\left(-58 \mathrm{mV}\right.$ ) under $I_{\mathrm{h}}$ block or $I_{\mathrm{K}-\mathrm{LVA}}$ block with a bias current. The peak EPSC amplitude is adjusted to obtain a mean train peak amplitude of $9 \mathrm{mV}$ under all three conditions. Bottom, Time course of input resistance $R_{\mathrm{N}}$ during and after the input train. $R_{\mathrm{N}}$ is computed for short (10 ms) pulses at $V_{\text {aft }}$ (solid curves) or at $V_{\text {rest }}=-58 \mathrm{mV}$ (dashed curves). Note that both $R_{\mathrm{N}}$ measurements overlap under DTX-K conditions. $\boldsymbol{B}$, Relative increases in $R_{\mathrm{N}}$ during and after EPSC trains, with $R_{\mathrm{N}}$ determined at $V_{\text {aft }}$. Same data as in $\boldsymbol{A}$ (solid curves), computed relative to initial $R_{\mathrm{N}}$ values. C, Relative increases in $R_{\mathrm{N}}$ during and after EPSC trains, with $R_{\mathrm{N}}$ determined at resting potential $V_{\text {rest }}=-58 \mathrm{mV}$ (see dashed curves in bottom of $A$ ).
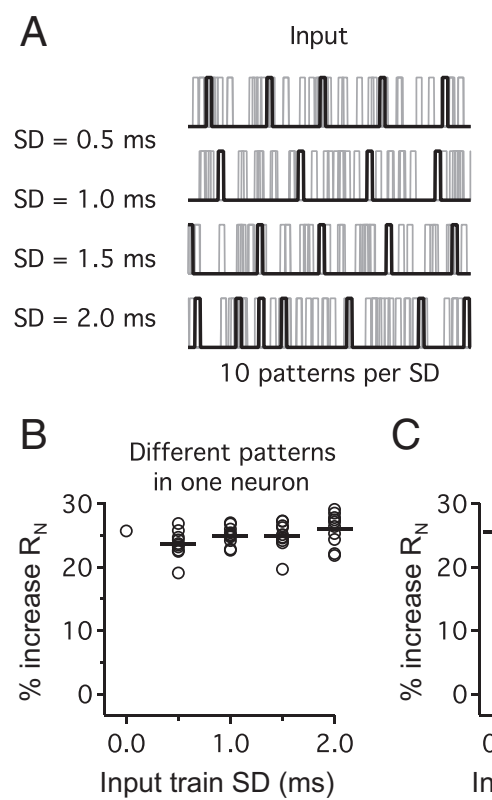

C

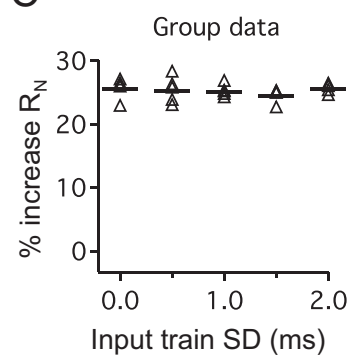

Representative responses (only 1 shown for each SD)

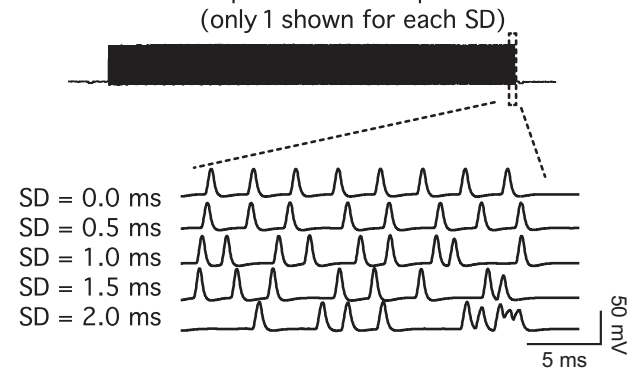

D

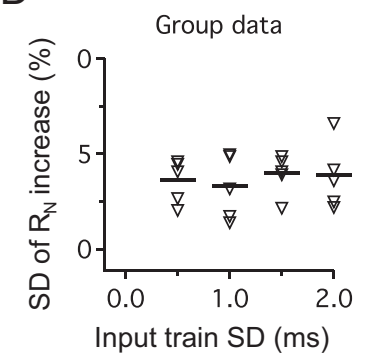

would be expected during the trains. However, in whole-cell current-clamp recordings, the EPSP amplitude during the train was surprisingly stable. Responses to $500 \mathrm{~Hz}$ trains of sEPSCs (2 s duration) showed a small, transient decrease in amplitude attributable to the activation of $I_{\mathrm{K}-\mathrm{LVA}}$, followed by a slow increase close to the original amplitude (Fig. 7A-C). Besides the EPSP amplitude, also the duration of individual EPSPs was stable, showing only a very small frequency-dependent increase $(<100 \mu \mathrm{s})$ (Fig. 7D).

The nearly uniform response to subthreshold sEPSCs seems at odds with the increase in input resistance that we observed during trains (Fig. 4). In fact, EPSP responses are riding on a gradually developing small hyperpolarization of the resting potential. This hyperpolarization gets occluded during summation of highfrequency inputs but is observable at the termination of the train (Fig. 4C) and was displayed in the model by the after-train potential $V_{\text {aft }}$ (Fig. 5A, green trace)

Alternatively, the constant EPSP amplitude can be easily understood by using the MSO cell model and focusing on the response to a steady current injection representing the mean current during an EPSC train. For example, during a $0.5 \mathrm{nA}$ current step, $I_{\mathrm{h}}$ and $I_{\mathrm{K}-\mathrm{LVA}}$ and their conare determined by the average level of synaptic excitation and insensitive to its fine temporal structure.

\section{$I_{\mathrm{K}-\mathrm{LVA}}$ and $I_{\mathrm{h}}$ interaction during trains maintains nearly constant EPSP amplitude and width}

Given the substantial $I_{\mathrm{K}-\mathrm{LVA}}$ inactivation and $I_{\mathrm{h}}$ deactivation induced by EPSP trains, a significant change in EPSP amplitude

ductances decrease significantly, whereas $V$ and $I_{\mathrm{h}}+I_{\mathrm{K} \text {-LVA }}$ vary little (Fig. $8 \mathrm{~A}$, solid lines), as seen previously for a $500 \mathrm{~Hz}$ EPSC train input (Fig. 3). The decreases in $I_{\mathrm{h}}$ and in the activated $I_{\mathrm{K} \text {-LVA }}$ during the input step counteract each other, enabling the constant $I_{\mathrm{h}}+I_{\mathrm{K}-\mathrm{LVA}}$ and constant $4 \mathrm{mV}$ mean depolarization. However, the voltage ranges for gating of $I_{\mathrm{h}}$ and $I_{\mathrm{K} \text {-LVA }}$ are different, so there is a limit to these balanced changes in current amplitude. 
For stronger current steps, $V$ evolves to a more depolarized level, as illustrated by using a threefold larger current step (Fig. $8 \mathrm{~A}$, dotted lines). After the initial depolarization to $-49 \mathrm{mV}, I_{\mathrm{h}}$ and $I_{\mathrm{K} \text {-LVA }}$ decrease on similar timescales but they are not counterbalanced in amplitude (middle). Although the sum, $I_{\mathrm{h}}+I_{\mathrm{K}-\mathrm{LVA}}$, after a small transient (200-300 ms) is nearly constant, $I_{\mathrm{h}}$ is significantly smaller because of its strong deactivation (bottom) and because $V$ approaches the reversal potential for $I_{\mathrm{h}}\left(E_{\mathrm{h}}\right.$ $=-37 \mathrm{mV}$ ). The steady-state response is 4 $\mathrm{mV}$ more depolarized than just after step onset and is dominated by $I_{\mathrm{K}-\mathrm{LVA}}$ because $g_{\mathrm{K}-\mathrm{LVA}}$ does not totally inactivate. These responses to larger steady input currents are predictive of responses to higher-frequency EPSC trains.

The initial and steady voltage responses to steady current inputs are easily predicted from the instantaneous and steady-state current-voltage relations of the membrane (Fig. $8 B$ ) (see Materials and Methods). Just after input onset, the membrane potential jumps from $V_{\text {rest }}$ to $V$ on the instantaneous $I-V$ curve (downward pointing triangle) and then slowly evolves to $V$ on the steady-state $I-V$ curve (upward pointing triangle). We see that, for modest current injections (e.g., $<1 \mathrm{nA}$ ), we can expect a nearly constant mean voltage response, whereas stronger input currents (e.g., 1.5 $\mathrm{nA}$ ) lead to cumulative depolarization during the input step.

Although this analysis helps us to understand the relative insensitivity of mean voltage alongside significant change in input resistance during a sustained moderate-sized input, it does not speak to the near constant amplitude of EPSP transients. We therefore ask whether small but fast transient inputs are affected by the gradual input resistance changes. By using a linearized approximation (see Materials and Methods), we find that the impedance for high frequencies is barely influenced from the start to the end of the $0.5 \mathrm{nA}$ injection in Figure $8 \mathrm{~A}$; above $\sim 500 \mathrm{~Hz}$, the gain is dominated by the capacitive current (results not shown).

\section{Coincidence detection and temporal resolution during ongoing stimuli}

In the MSO neuron model, although $V$ changes little during long, modest input steps, the decreasing conductance of $I_{\mathrm{h}}$ and $I_{\mathrm{K}-\mathrm{LVA}}$ results in a slowly increasing input resistance $R_{\mathrm{N}}$ [measured at $V(t)]$. For a $1 \mathrm{nA}$ input, the membrane will gradually depolarize by $1.6 \mathrm{mV}$ during the step, whereas $R_{\mathrm{N}}$ gradually increases by $46 \%$ (Fig. 9A). The initial drop in $R_{\mathrm{N}}$ is attributable to the rapid activation of $g_{\text {K-LVA }}$. To address the possible consequences of changing $R_{\mathrm{N}}$ for integration of synaptic inputs, we viewed these steady depolarizations as an idealization for an asynchronous background of synaptic currents. How might the adaptation of intrinsic conductances, the slowly increasing $R_{\mathrm{N}}$, affect coincidence detection for two transient inputs that are superimposed on the background? We simulated this condition by superimposing noise on the constant mean $1 \mathrm{nA}$ input along with EPSC pairs separated in time by $\Delta t \mathrm{~ms}$. The resulting firing probability versus $\Delta t$ at later time points (greater $R_{\mathrm{N}}$ ) shows an increased excitability (higher firing probability) and a nearly $100 \%$ broader half-width of this coincidence detection tuning function (Fig. 9B, "Uniform EPSC ampl.”).
We also determined the firing probability in consideration of an idealized representation of synaptic depression by providing decreasing amplitude EPSC pairs with time of the pulse. We computed the tuning functions by using EPSC amplitudes adjusted so that with $\Delta t=0$ the firing probabilities are matched. This approach resulted in tuning functions that were nearly identical (Fig. 9B, "Adjusted EPSC ampl."; see inset for adjusted EPSC amplitudes). The same results were obtained when EPSC pairs were incorporated in EPSC trains (data not shown). These results indicate that the temporal precision of EPSPs does not degrade significantly over time and that broadening of the tuning functions for uniform amplitude EPSCs is attributable to an increase in spike probability. Hence, whether the coincidence window broadens or remains constant depends on how synaptic EPSC amplitude evolves over time, which is determined by several factors, e.g., synaptic depression, and presynaptic adaptation affecting the number of activated synaptic inputs.

Finally, we verified the predictions of the model using current-clamp recordings of MSO principal neurons. We provided a square current injection that produced a nearly $7 \mathrm{mV}$ depolarization and added Gaussian noise of $1.6 \mathrm{mV}$ SD. Two sEPSCs separated in time by $\Delta t$ ms were injected at 50,250 , or $1950 \mathrm{~ms}$ after onset of the square current pulse. When all EPSC injections have identical amplitude, we find, as in the model, that the firing probability increased over time, broadening the tuning of coincidence detection (Fig. 9C, "Uniform EPSC ampl."). Adjusting the EPSC amplitudes such that firing probability at $\Delta t=0$ is matched also shows maintenance of the coincidence window (Fig. 9C, “Adjusted EPSC ampl.”).

Several factors, mediated by the input resistance increase during sustained input, contribute to the enhanced excitability. In addition to modest increases of mean membrane potential and individual EPSPs as seen without noise present, the variance of membrane potential fluctuations increases during a noisy background. The chance occurrence of sequential depolarizing input fluctuations enables the input resistance to influence temporal summation beyond the effect of individual events. These effects together lead to excitability increases that reflect the $>50 \%$ increase in input resistance. 

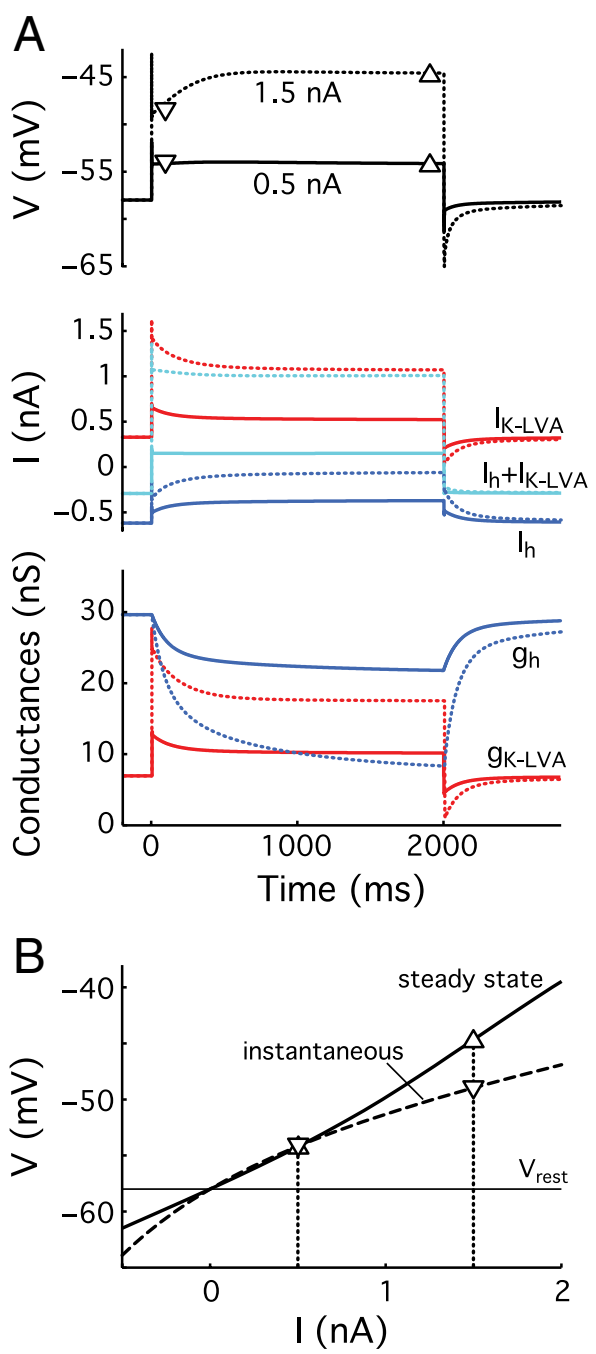

Figure 8. Evolution of membrane potential during steady current input in MSO cell model. $\boldsymbol{A}$, Voltage (top), voltage-dependent currents (middle), and conductances (bottom) during a simulation of a $2 \mathrm{~s}$ current step of $0.5 \mathrm{nA}$ (solid lines) or $1.5 \mathrm{nA}$ (dotted lines). Initial voltage and steady-state voltage during current step are marked by downward and upward pointing triangles. Middle shows $I_{\mathrm{h}}$ (blue), $I_{\mathrm{K}-\mathrm{LVA}}\left(\right.$ red), and their sum (light blue). Bottom shows $g_{\mathrm{h}}$ (blue) and $g_{\mathrm{K}-\mathrm{LVA}}(\mathrm{red})$. Note that the mean input current amplitude in the simulation in Figure 3 is $0.69 \mathrm{pA}$. $\boldsymbol{B}$, Instantaneous (dashed line) and steady-state (solid line) voltage during a current step. Triangles mark voltage responses for 0.5 and $1.5 \mathrm{nA}$ input steps and correspond to responses in $\boldsymbol{A}$. For computation of instantaneous and steady-state voltage, see Materials and Methods.

\section{Discussion}

In MSO principal cells, the encoding of sound localization cues requires the detection of the ongoing temporal registry of binaural synaptic inputs. In this study, we found that, during trains of EPSPs over a range of amplitudes and frequencies, a dynamic interaction between $I_{\mathrm{h}}$ and $I_{\mathrm{K}-\mathrm{LVA}}$ imparts greater uniformity to the amplitude and shape of EPSPs than would be achieved by the effects of either of the individual currents alone. The nearly stable amplitude of EPSPs during trains occurred in the face of significant increases in input resistance that developed and decayed over hundreds of milliseconds. In both model and experiments, an increase in spike probability mediated by increasing input resistance and modest depolarization during noisy stimulus trains broadened the window for detecting the coincidence of bilateral synaptic stimuli, but this broadening could be eliminated by incorporating a small degree of short-term synaptic depression. We conclude that the interplay between $I_{\mathrm{h}}$ and $I_{\mathrm{K}-\mathrm{LVA}}$ acts as a homeostatic mechanism during sustained stimulation to preserve an operational mean voltage range and EPSP amplitude; temporal precision of synaptic integration and coincidence detection can be maintained if assisted by some input adaptation, such as short-term synaptic depression.

\section{Interactions between $I_{\mathrm{h}}$ and potassium currents in neurons}

In many neurons, $I_{\mathrm{h}}$ gives rise to a non-inactivating, depolarizing current that is partially activated at the resting potential. Given that $I_{\mathrm{h}}$ exhibits reversal potentials between -20 and $-40 \mathrm{mV}, I_{\mathrm{h}}$ increases cell excitability by depolarizing the membrane potential toward action potential threshold. However, several studies have shown that the impact of $I_{\mathrm{h}}$ on cell excitability is more complex. In hippocampal and neocortical pyramidal neurons, in which HCN channels are expressed in high density in the distal dendrites (Magee, 1998; Lörincz et al., 2002; Kole et al., 2006), during trains of EPSPs the net outward current from $I_{\mathrm{h}}$ deactivation shortens EPSPs, reduces temporal summation, and decreases the probability of firing (Stuart and Spruston, 1998; Magee, 1999). Similar results have been observed in several cell types in the auditory system, including bushy cells of the cochlear nucleus, principal neurons of the medial nucleus of the trapezoid body, and neurons of the inferior colliculus (Koch and Grothe, 2003; R. N. Leao et al., 2005; K. E. Leao et al., 2006). In CA1 pyramidal neurons, George et al. (2009) have shown that activation of M-type potassium channels can render the influence of $\mathrm{HCN}$ channels dependent on the amplitude and time course of EPSPs. Although the resting depolarization of $I_{\mathrm{h}}$ is excitatory, bringing smaller EPSPs closer to firing threshold, larger EPSPs can activate M-current $\left(I_{\mathrm{M}}\right)$, suppress peak depolarizations, and thus reduce temporal and spatial summation (George et al., 2009). Both $I_{\mathrm{h}}$ and $I_{\mathrm{M}}$ affect the amplitude and time course of excitation because of the temporal overlap between EPSPs and the gating of the channels.

The influence of $I_{\mathrm{h}}$ is different in MSO principal neurons compared with the neurons described above because the time course of individual EPSCs is in the submillisecond range (Smith et al., 2000; Magnusson et al., 2005; Couchman et al., 2010), far briefer than the activation and deactivation kinetics of $I_{\mathrm{h}}$ (time constant of $\sim 100 \mathrm{~ms}$ at the resting potential in MSO neurons). As a result, deactivation of $I_{\mathrm{h}}$ occurs only cumulatively during trains of EPSPs. This hyperpolarizing effect is counterbalanced by two factors: the depolarization from cumulative inactivation of $I_{\mathrm{K}-\mathrm{LVA}}$ and an increase in input resistance, mediated by the inactivation of $I_{\mathrm{K}-\mathrm{LVA}}$ and deactivation of $I_{\mathrm{h}}$. Thus, whereas in other neurons interactions between potassium currents and $I_{\mathrm{h}}$ distort the time course of EPSPs over time, in MSO principal neurons EPSP amplitudes are nearly uniform.

The stabilizing influence of $I_{\mathrm{h}}$ and $I_{\mathrm{K}-\mathrm{LVA}}$ on the amplitude and duration of EPSPs during trains requires that not only must the underlying channels make strong contributions to the overall resting conductance but the magnitudes of the currents must be approximately matched. Simulations with our MSO cell model in which we varied the ratio of $g_{\mathrm{h}}$ and $g_{\mathrm{K}-\mathrm{LVA}}$ over a wide range displayed a gradual transition (results not shown) from the balanced dynamics observed in real MSO neurons to responses that are similar to the experiments in which we blocked either channel. Considerable cell-to-cell variability in the magnitude of $I_{\mathrm{h}}$ and $I_{\mathrm{K}-\mathrm{LVA}}$ was observed across different MSO neuron recordings, but these experiments do not reveal whether the expression of the two channel types is linked. There is precedent for such a linkage, however. In invertebrate neurons, the expression of $I_{\mathrm{h}}$ 
has been shown to be coordinated with that of A-type potassium channels to maintain comparable firing patterns (MacLean et al., 2005). It is also important to note that both $I_{\mathrm{h}}$ and $I_{\mathrm{K} \text {-LVA }}$ are sensitive to a wide range of intracellular modulators (for review, see Kaczmarek et al., 2005; Wahl-Schott and Biel, 2009), which may provide MSO neurons with additional mechanisms by which to adjust the magnitude of resting conductances.

The interactions we have described between $I_{\mathrm{h}}$ and $I_{\mathrm{K} \text {-LVA }}$ are applicable to other neuron types in the mammalian auditory system. However, the similarities in intrinsic electrical properties are particularly striking in octopus cells of the ventral cochlear nucleus and principal neurons of the lateral superior olive. Both of these cell types integrate high-frequency trains of brief excitatory synaptic inputs, and $I_{\mathrm{h}}$ and $I_{\mathrm{K}-\mathrm{LVA}}$ make strong contributions to the resting potential (Bal and Oertel, 2000; Hassfurth et al., 2009). Thus, in these neurons, interactions between $I_{\mathrm{h}}$ and $I_{\text {K-LVA }}$ could serve to stabilize trains of synaptic stimuli in a similar manner as in MSO principal neurons.

\section{Comparison with avian binaural coincidence detectors}

Both $I_{\mathrm{h}}$ and $I_{\mathrm{K}-\mathrm{LVA}}$ are coexpressed in neurons of the nucleus laminaris, the avian analog of mammalian bushy cells and MSO principal neurons (Reyes et al., 1994; Kuba et al., 2005; Yamada et al., 2005). In these neurons, inactivation of $I_{\mathrm{K}-\mathrm{LVA}}$ during long synaptic input trains enhances the firing rate, increasing intrinsic gain at the expense of temporal precision (Kuznetsova et al., 2008). In MSO principal neurons, we also observed an increase in intrinsic gain (observed as an increase in firing probability during uniform EPSCs), but changes in the rise time and duration of the underlying EPSPs were relatively subtle. Some of the differences in synaptic integration during trains between birds and mammals may be related to $I_{\mathrm{h}}$, which is smaller in nucleus laminaris neurons and exhibits a more hyperpolarized activation range (Yamada et al., 2005). These differences would affect synaptic precision because both the conductance underlying $I_{\mathrm{h}}$ reduces the membrane time constant and $I_{\mathrm{h}}$ depolarizes the resting potential into the activation range of $I_{\mathrm{K}-\mathrm{LVA}}$. Furthermore, because $I_{\mathrm{h}}$ contributes less to the resting membrane conductance in nucleus laminaris neurons, the inactivation of $I_{\mathrm{K}-\mathrm{LVA}}$ during long excitatory trains would not be counteracted as strongly by the slow deactivation of $I_{\mathrm{h}}$, leading to stronger cumulative depolarizations, increased spike probability, and potentially a time-dependent widening of the window for binaural coincidence detection. Together, these findings indicate that, although there are many similar specializations in mammals and birds for achieving submillisecond binaural time resolution, these
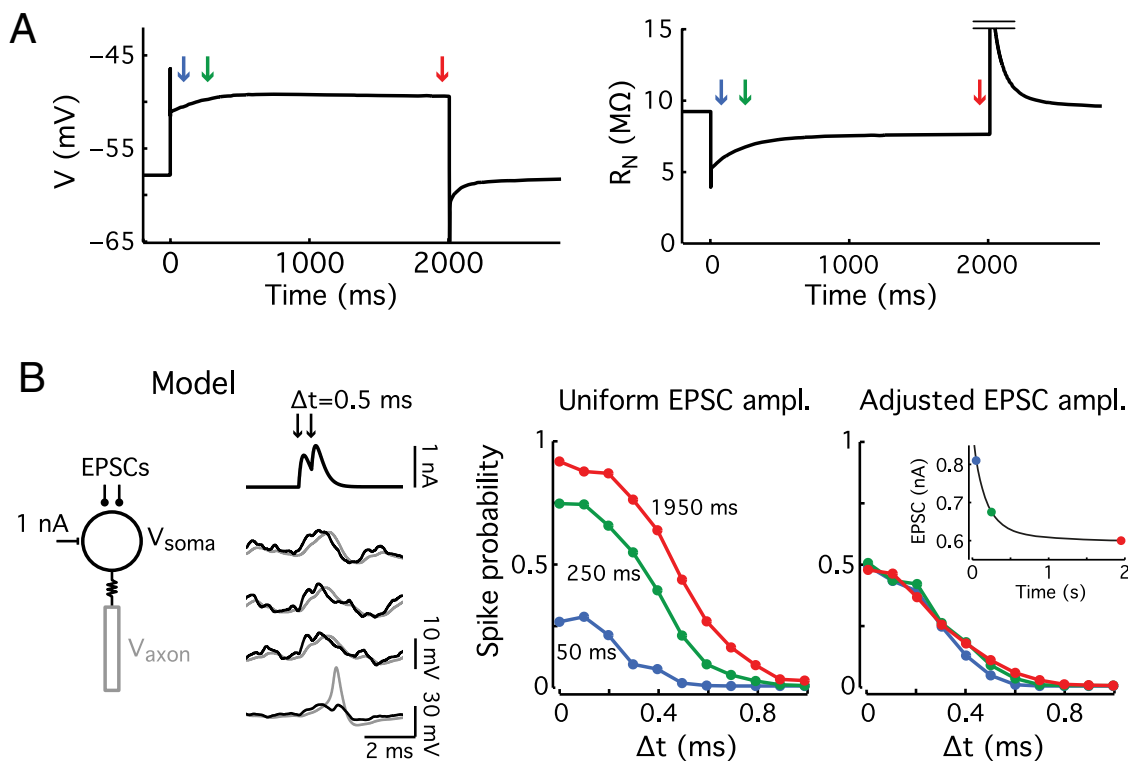

\section{Experiment}
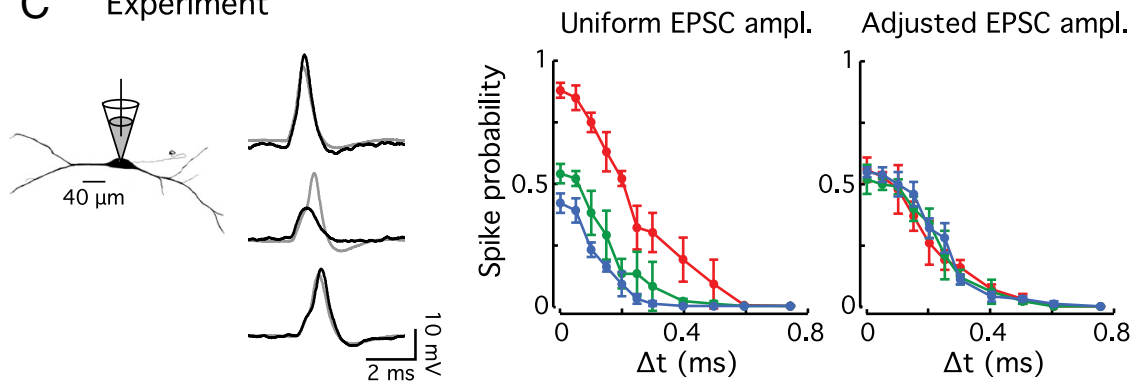

Figure 9. Evaluation of coincidence window during depolarizing activity. $\boldsymbol{A}$, Voltage response (left) and input resistance (right) to a $1 \mathrm{nA}$ current step in the MSO cell model. The input resistance is computed for short pulses at voltage $V(t)$ (see Materials and in the MSO cell model. To compute the response curves, a noise current is added to the soma and the model is extended with an axonal compartment that includes action-potential-generating currents (left diagram and see Materials and Methods). Traces responses determined $250 \mathrm{~ms}$ after the input step onset. Panels show spike probability for EPSC pairs with interval $\Delta t$, computed spike probability at $\Delta t=0$. Inset in right shows adjusted EPSC amplitudes $(810,675$, and $600 \mathrm{pA})$ used for the three for full 2 s range, using a sum of two exponentials with time constants of 101 and $295 \mathrm{~ms}$. EPSC time constant is $0.2 \mathrm{~ms}$, and spike probability is computed over 600 trials. C, In whole-cell somatic recordings, $10-20$ iterations of $7 \mathrm{mV}$ noisy depolarizing steps with to an EPSC pair with $\Delta t=0.1 \mathrm{~ms}$. Both the responses to the stimulus without noise (gray) and to the stimulus with noise of $1.6 \mathrm{mV}$ SD (black). Right shows $\Delta t$-response curves for EPSC transients with uniform peak amplitude (left) and with adjusted peak amplitudes (right) such that each condition gives $\sim 50 \%$ spike probability at $\Delta t=0$.

circuits also exhibit significant differences that likely reflect their independent evolution (Grothe, 2003).

\section{Implications for interaural time-delay coding}

Central to sound localization by MSO neurons is their ability to detect coincident inputs. We find that the width of the window for detecting bilateral synaptic coincidence gradually broadens by up to $100 \%$ during an ongoing depolarizing stimulus. This effect is mediated by the cumulative increase in input resistance and modest depolarization that can amplify EPSPs that summate or ride on noise, increasing spike probability. When we decreased EPSC amplitudes such that firing probability for precisely coincident $\operatorname{EPSCs}(\Delta t=0)$ remained constant over time, the width of the coincidence window remained constant during the ongoing stimulus, in both simulations 
and experiments. This means that, despite the slowly decreasing membrane conductance resulting from cumulative decreases of $I_{\mathrm{h}}$ and $I_{\mathrm{K}-\mathrm{LVA}}$, the rise time and duration of individual EPSPs is not altered significantly during the integration of ongoing stimuli.

Importantly, the width of the coincidence window will depend on how the amplitude of synaptic input changes during ongoing stimuli. One important factor determining these changes is shortterm synaptic plasticity (Neher, 2008). Studies in the avian auditory system suggest an important role for synaptic depression, which provides an adaptive mechanism for preserving interaural time-delay information independent of sound intensity (Cook et al., 2003; Grande and Spain, 2005). Depression of the synaptic inputs to MSO cells would counteract the increases in excitability and impose a narrower time window for binaural coincidence. However, the magnitude of synaptic depression in time-coding auditory neurons is controversial (Borst, 2010). In MSO principal neurons in vitro, short-term depression of inhibitory and excitatory synaptic currents appears well matched in amplitude and time course and exceeds $50 \%$ at frequencies $>100 \mathrm{~Hz}$ (Couchman et al., 2010). However, these results must be tempered with the finding that short-term depression has been found to be far less prominent in vivo than in unstimulated slices (Lorteije et al., 2009). The balance for MSO principal neurons between the slow dynamics of $I_{\mathrm{h}}, I_{\mathrm{K}-\mathrm{LVA}}$, and other adaptation mechanisms, such as synaptic depression, remains a complex but important future issue.

\section{References}

Bal R, Oertel D (2000) Hyperpolarization-activated, mixed-cation current $\left(\mathrm{I}_{\mathrm{h}}\right)$ in octopus cells of the mammalian cochlear nucleus. J Neurophysiol 84:806-817.

Bal R, Oertel D (2001) Potassium currents in octopus cells of the mammalian cochlear nucleus. J Neurophysiol 86:2299-2311.

Banks MI, Smith PH (1992) Intracellular recordings from neurobiotinlabeled cells in brain slices of the rat medial nucleus of the trapezoid body. J Neurosci 12:2819-2837.

Barnes-Davies M, Barker MC, Osmani F, Forsythe ID (2004) Kv1 currents mediate a gradient of principal neuron excitability across the tonotopic axis in the rat lateral superior olive. Eur J Neurosci 19:325-333.

Borst JG (2010) The low synaptic release probability in vivo. Trends Neurosci 33:259-266.

Cook DL, Schwindt PC, Grande LA, Spain WJ (2003) Synaptic depression in the localization of sound. Nature 421:66-70.

Couchman K, Grothe B, Felmy F (2010) Medial superior olivary neurons receive surprisingly few excitatory and inhibitory inputs with balanced strength and short-term dynamics. J Neurosci 30:17111-17121.

George MS, Abbott LF, Siegelbaum SA (2009) HCN hyperpolarizationactivated cation channels inhibit EPSPs by interactions with M-type $\mathrm{K}^{+}$ channels. Nat Neurosci 12:577-584.

Golding NL, Robertson D, Oertel D (1995) Recordings from slices indicate that octopus cells of the cochlear nucleus detect coincident firing of auditory nerve fibers with temporal precision. J Neurosci 15:3138-3153.

Grande LA, Spain WJ (2005) Synaptic depression as a timing device. Physiology (Bethesda) 20:201-210.

Grothe B (2003) New roles for synaptic inhibition in sound localization. Nat Rev Neurosci 4:540-550.

Hassfurth B, Magnusson AK, Grothe B, Koch U (2009) Sensory deprivation regulates the development of the hyperpolarization-activated current in auditory brainstem neurons. Eur J Neurosci 30:1227-1238.

Joris P, Yin TC (2007) A matter of time: internal delays in binaural processing. Trends Neurosci 30:70-78.

Joris PX, Carney LH, Smith PH, Yin TC (1994) Enhancement of neural synchronization in the anteroventral cochlear nucleus. I. Responses to tones at the characteristic frequency. J Neurophysiol 71:1022-1036.

Kaczmarek LK, Bhattacharjee A, Desai R, Gan L, Song P, von Hehn CA, Whim MD, Yang B (2005) Regulation of the timing of MNTB neurons by short-term and long-term modulation of potassium channels. Hear Res 206:133-145.

Koch U, Grothe B (2003) Hyperpolarization-activated current $\left(I_{h}\right)$ in the inferior colliculus: distribution and contribution to temporal processing. J Neurophysiol 90:3679-3687.
Kole MH, Hallermann S, Stuart GJ (2006) Single $I_{\mathrm{h}}$ channels in pyramidal neuron dendrites: properties, distribution, and impact on action potential output. J Neurosci 26:1677-1687.

Kuba H, Yamada R, Fukui I, Ohmori H (2005) Tonotopic specialization of auditory coincidence detection in nucleus laminaris of the chick. J Neurosci 25:1924-1934.

Kuznetsova MS, Higgs MH, Spain WJ (2008) Adaptation of firing rate and spiketiming precision in the avian cochlear nucleus. J Neurosci 28:11906-11915.

Leao KE, Leao RN, Sun H, Fyffe RE, Walmsley B (2006) Hyperpolarizationactivated currents are differentially expressed in mice brainstem auditory nuclei. J Physiol 576:849-864.

Leao RN, Svahn K, Berntson A, Walmsley B (2005) Hyperpolarizationactivated $\left(I_{\mathrm{h}}\right)$ currents in auditory brainstem neurons of normal and congenitally deaf mice. Eur J Neurosci 22:147-157.

Lörincz A, Notomi T, Tamás G, Shigemoto R, Nusser Z (2002) Polarized and compartment-dependent distribution of $\mathrm{HCN} 1$ in pyramidal cell dendrites. Nat Neurosci 5:1185-1193.

Lorteije JA, Rusu SI, Kushmerick C, Borst JG (2009) Reliability and precision of the mouse calyx of Held synapse. J Neurosci 29:13770-13784.

MacLean JN, Zhang Y, Goeritz ML, Casey R, Oliva R, Guckenheimer J, Harris-Warrick RM (2005) Activity-independent coregulation of $\mathrm{I}_{\mathrm{A}}$ and $\mathrm{I}_{\mathrm{h}}$ in rhythmically active neurons. J Neurophysiol 94:3601-3617.

Magee JC (1998) Dendritic hyperpolarization-activated currents modify the integrative properties of hippocampal CAl pyramidal neurons. J Neurosci 18:7613-7624.

Magee JC (1999) Dendritic $I_{\mathrm{h}}$ normalizes temporal summation in hippocampal CA1 neurons. Nat Neurosci 2:848.

Magnusson AK, Kapfer C, Grothe B, Koch U (2005) Maturation of glycinergic inhibition in the gerbil medial superior olive after hearing onset. J Physiol 568:497-512.

Mathews PJ, Jercog PE, Rinzel J, Scott LL, Golding NL (2010) Control of submillisecond synaptic timing in binaural coincidence detectors by $\mathrm{K}_{\mathrm{v}} 1$ channels. Nat Neurosci 13:601-609.

Mo ZL, Davis RL (1997) Heterogeneous voltage dependence of inward rectifier currents in spiral ganglion neurons. J Neurophysiol 78:3019-3027.

Neher E (2008) Details of $\mathrm{Ca}^{2+}$ dynamics matter. J Physiol 586:2031.

Rathouz M, Trussell L (1998) Characterization of outward currents in neurons of the avian nucleus magnocellularis. J Neurophysiol 80:2824-2835.

Reyes AD, Rubel EW, Spain WJ (1994) Membrane properties underlying the firing of neurons in the avian cochlear nucleus. J Neurosci 14:5352-5364.

Rothman JS, Manis PB (2003a) Kinetic analyses of three distinct potassium conductances in ventral cochlear nucleus neurons. J Neurophysiol 89:3083-3096.

Rothman JS, Manis PB (2003b) The roles potassium currents play in regulating the electrical activity of ventral cochlear nucleus neurons. J Neurophysiol 89:3097-3113.

Scott LL, Mathews PJ, Golding NL (2005) Posthearing developmental refinement of temporal processing in principal neurons of the medial superior olive. J Neurosci 25:7887-7895.

Scott LL, Hage TA, Golding NL (2007) Weak action potential backpropagation is associated with high-frequency axonal firing capability in principal neurons of the gerbil medial superior olive. J Physiol 583:647-661.

Scott LL, Mathews PJ, Golding NL (2010) Perisomatic voltage-gated sodium channels actively maintain linear synaptic integration in principal neurons of the medial superior olive. J Neurosci 30:2039-2050.

Smith AJ, Owens S, Forsythe ID (2000) Characterisation of inhibitory and excitatory postsynaptic currents of the rat medial superior olive. J Physiol 529:681-698.

Stuart G, Spruston N (1998) Determinants of voltage attenuation in neocortical pyramidal neuron dendrites. J Neurosci 18:3501-3510.

Svirskis G, Kotak V, Sanes DH, Rinzel J (2002) Enhancement of signal-tonoise ratio and phase locking for small inputs by a low-threshold outward current in auditory neurons. J Neurosci 22:11019-11025.

Svirskis G, Kotak V, Sanes DH, Rinzel J (2004) Sodium along with lowthreshold potassium currents enhance coincidence detection of subthreshold noisy signals in MSO neurons. J Neurophysiol 91:2465-2473.

Wahl-Schott C, Biel M (2009) HCN channels: structure, cellular regulation and physiological function. Cell Mol Life Sci 66:470-494.

Willms AR (2002) NEUROFIT: software for fitting Hodgkin-Huxley models to voltage-clamp data. J Neurosci Methods 121:139-150.

Yamada R, Kuba H, Ishii TM, Ohmori H (2005) Hyperpolarization-activated cyclic nucleotide-gated cation channels regulate auditory coincidence detection in nucleus laminaris of the chick. J Neurosci 25:8867-8877. 